\title{
Synthesis and Biological Evaluation of Novel Betulin Derivatives with Aromatic Hydrazone Side Chain as Potential Anticancer Agents
}

\author{
Jiafeng Wang, ${ }^{a}$ Jiale Wu, ${ }^{a}$ Yinglong Han, ${ }^{a}$ Jie Zhang, ${ }^{a}$ Yu Lin, ${ }^{a}$ Haijun Wang, ${ }^{a}$ \\ Jing Wang ${ }^{a}$ and Ming $B u^{\circledR *, a}$ \\ ${ }^{a}$ College of Pharmacy, Qiqihar Medical University, 161006 Qiqihar, China
}

\begin{abstract}
A series of novel betulin-28-hydrazone derivatives (7a-7o) were synthesized. All compounds were evaluated for their in vitro cytotoxicities in four human carcinoma cells (HepG2, MCF-7, HCT-116 and A549). Among them, compound 7l displayed the most potent cytotoxicity with an $\mathrm{IC}_{50}$ (concentration of the tested compound that inhibits $50 \%$ of cell growth) value of $7.37 \pm 0.38 \mu \mathrm{M}$ against MCF-7 cells. The preliminary cellular mechanism studies indicated that compound $7 \mathbf{l}$ could induce MCF-7 cells apoptosis. The above findings indicated that compound $7 \mathbf{l}$ may be used as a lead compound for antitumor agents with improved efficacy.
\end{abstract}

Keywords: betulin derivatives, hydrazone, heterocycles, antitumor, apoptosis

\section{Introduction}

Nowadays, cancer has become the second leading cause of death worldwide. ${ }^{1}$ The most effective of therapies used in cancer treatment continue to be traditional cytotoxic agents. ${ }^{2}$ It is worth noting that the discovery of potent anticancer drugs from natural sources is still one of the important directions in the field of drug research. ${ }^{3-5}$ Betulin (lup-20(29)-ene-3ß,28-diol, BE, 1) is an important natural lupine-type triterpenoid widely distributed in plenty of plants, especially abundant in the bark of birch trees (Figure 1). ${ }^{6}$ Betulin has been shown to exert various pharmacological and biological activities, such as antibacterial, anti-HIV (human immunodeficiency virus) and anti-inflammatory properties..$^{7-15}$ Recently, a plenty of studies ${ }^{16-26}$ have reported that betulin and its derivatives present significant antitumor activities against kinds of human cancer cell lines, such as colorectal carcinoma (HT29, HCT116), lung (A549), liver (SK-HEP-1, HepG2), breast (MCF-7, MDA-MB231), prostate (PC3), as well as cervical (HeLa) and leukemia (HL-60, K562, U937). However, the high hydrophobicity of betulin hampers its further development as cytotoxic drug. There are three active positions in betulin structure, namely the isopropenyl side chain at C-19, and two hydroxyl groups at C-3 and C-28. It is quite possible to make chemical modification of these positions to obtain novel betulin derivatives with desired biological properties.

*e-mail: buming@qmu.edu.cn

Editors handled this article: Teodoro S. Kaufman and Brenno A. D. Neto (Associate)

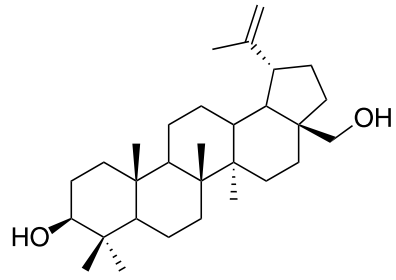

Figure 1. Structure of betulin (BE, 1).

It is well known that hydrazine, hydrazone and their derivatives are series of highly active molecules, which have attracted considerable attention of medicinal chemists for the development of new anti-cancer drugs. ${ }^{27-32}$ An overall survey of the structure of a hydrazone shows that it has (i) nucleophilic imine and amino-type nitrogens, (ii) an imine carbon that has both electrophilic and nucleophilic character, (iii) configurational isomerism stemming from the intrinsic nature of the $\mathrm{C}=\mathrm{N}$ double bond, and (iv) in most cases an acidic $\mathrm{N}-\mathrm{H}$ proton (Figure 2). These features give the hydrazone group its physical and chemical properties, in addition to playing a crucial part in determining the range of applications it can be involved in. ${ }^{33}$ In addition, heterocycles are important structural units present in many drugs. They possess hydrogen bond donors and acceptors in a rigid framework, and they can therefore effectively interact with target enzymes and receptors via hydrogen bond interactions. ${ }^{34-37}$

Thus, inspired by good biological property of hydrazone and aromatic heterocycle, in view of the potential medicinal research value of betulin and in continuation of an ongoing program aiming at developing 


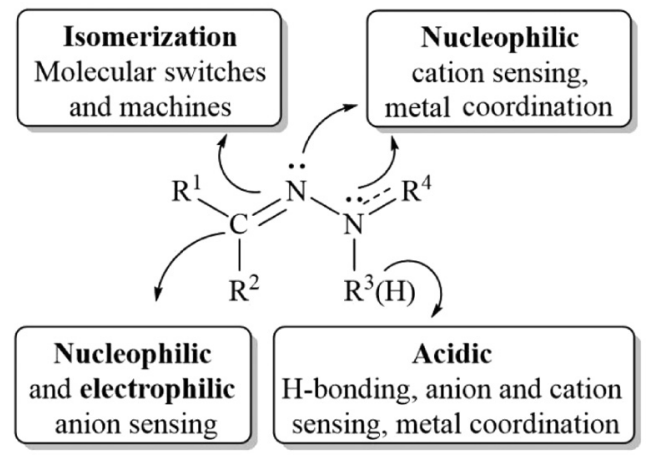

Figure 2. The structural and functional diversity of the hydrazone group.

more potential anticancer drugs, in the present study fifteen betulin derivatives modified at C-28 position with aromatic heterocycles were designed and synthesized. We hope to obtain more useful information about the influence of heterocycles at the $\mathrm{C}-28$ position on cytotoxic activity in the group of betulin and their underlying mechanisms of antitumor effect.

\section{Experimental}

\section{Chemistry}

All materials were purchased from commercial suppliers and used without further purification (Energy, Shanghai, China). Reaction progress was real-time monitored by thin-layer-chromatography (TLC) using F254 silica gel plates (Biohonor, Guangzhou, China). The intermediates and target compounds were purified by flash column chromatography using 300 mesh silica gel (Yinlong, Qingdao, China). Melting points (mp) were determined using an MP120 melting point apparatus (Haineng, Fujian, China) and were not corrected. ${ }^{1} \mathrm{H}$ and ${ }^{13} \mathrm{C}$ nuclear magnetic resonance (NMR) spectra were recorded with Bruker AVANCE NEO600 spectrometer (tetramethylsilane (TMS) as internal standard) (Bruker, Berlin, Germany). The chemical shifts were expressed in ppm. Low resolution mass spectra (MS) were recorded on Esquire 6000 mass spectrometer (Bruker, Berlin, Germany). High-resolution mass spectra (HRMS) were obtained using an Agilent 6250 mass spectrometer (Agilient, San Francisco, USA). The values of MS were recorded in a positive ion mode with electrospray ionization (ESI) source.

\section{3-0,28-O-Acetyl-betulin (2)}

To a solution of betulin $(1,3.10 \mathrm{~g}, 7.0 \mathrm{mmol})$ in pyridine $(80 \mathrm{~mL})$, it was added 4-dimethylaminopyridine (DMAP, $40 \mathrm{mg}, 0.3 \mathrm{mmol})$ and acetic anhydride $\left(\mathrm{Ac}_{2} \mathrm{O}\right.$, $2 \mathrm{~mL}, 24 \mathrm{mmol})$ at $0{ }^{\circ} \mathrm{C}$. The reaction was stirred at room temperature for $6 \mathrm{~h}$. The solution was evaporated and then redissolved with $\mathrm{CH}_{2} \mathrm{Cl}_{2}(100 \mathrm{~mL})$, washed with sat. $\mathrm{NaHCO}_{3}$. The combined solution was washed with brine twice and dried over anhydrous $\mathrm{Na}_{2} \mathrm{SO}_{4}$. The solvent was evaporated and purified by silica gel column chromatography (ethyl acetate/petroleum ether $=1 / 50$ ) to give $2(2.95 \mathrm{~g}, 80 \%)$. White solid; $\mathrm{mp} 216.0-217.5^{\circ} \mathrm{C}$; ${ }^{1} \mathrm{H} \mathrm{NMR}\left(600 \mathrm{MHz}, \mathrm{CDCl}_{3}\right) \delta 4.69$ (s, $\left.1 \mathrm{H},-\mathrm{C}=\mathrm{CH}\right), 4.59$ (s, $1 \mathrm{H},-\mathrm{C}=\mathrm{CH}), 4.47(\mathrm{dd}, 1 \mathrm{H}, J 10.6,5.7 \mathrm{~Hz}, \mathrm{AcO}-\mathrm{CH}), 4.25$ (d, $\left.1 \mathrm{H}, J 10.9 \mathrm{~Hz}, \mathrm{CH}_{2}-\mathrm{O}\right), 3.85\left(\mathrm{~d}, 1 \mathrm{H}, J 11.0 \mathrm{~Hz}, \mathrm{CH}_{2}-\mathrm{O}\right.$ ), 2.44 (td, $1 \mathrm{H}, J 11.1,5.8 \mathrm{~Hz}, \mathrm{H} 3$ ), 2.07 (s, $3 \mathrm{H}, \mathrm{CH}_{3}-\mathrm{COO}$ ), 2.04 (s, 3H, $\mathrm{CH}_{3}-\mathrm{COO}$ ), 1.68 (s, $3 \mathrm{H}, \mathrm{CH}_{3}-\mathrm{C}=\mathrm{C}$ ), 1.03 (s, $\left.3 \mathrm{H},-\mathrm{CH}_{3}\right), 0.97\left(\mathrm{~s}, 3 \mathrm{H},-\mathrm{CH}_{3}\right), 0.87-0.82\left(\mathrm{~m}, 9 \mathrm{H},-\mathrm{CH}_{3} \times 3\right)$, $0.78(\mathrm{~d}, 1 \mathrm{H}, J 9.3 \mathrm{~Hz}) ;{ }^{13} \mathrm{C} \mathrm{NMR}\left(150 \mathrm{MHz}, \mathrm{CDCl}_{3}\right) \delta 171.6$, 171.0, 150.2, 109.9, 80.9, 62.8, 55.4, 50.3, 48.8, 47.7, 46.3, $42.7,40.9,38.4,37.8,37.6,37.1,34.5,34.1,29.7,29.6,27.9$, 27.1, 25.2, 23.7, 21.3, 21.1, 20.8, 19.1, 18.2, 16.5, 16.2, 16.0, 14.7; MS (ESI) $m / z$, [M + H] $]^{+}: 527.4$.

\section{3-O-Acetyl-betulin (3)}

To a solution of 3-O,28-O-acetyl-betulin $(2,3.41 \mathrm{~g}$, $6.4 \mathrm{mmol})$ in isopropyl alcohol (i-PrOH, $160 \mathrm{~mL})$, it was added titanium propoxide $\left(\mathrm{Ti}(i-\mathrm{PrOH})_{4}, 10 \mathrm{~mL}, 35 \mathrm{mmol}\right)$. The reaction temperature was increased to $85^{\circ} \mathrm{C}$ and stirred for $5 \mathrm{~h}$. The solution was evaporated and then added $\mathrm{CH}_{2} \mathrm{Cl}_{2}$ $(50 \mathrm{~mL})$ and water $(50 \mathrm{~mL})$. The filtration was washed with brine twice and dried over anhydrous $\mathrm{Na}_{2} \mathrm{SO}_{4}$. The solvent was evaporated and purified by silica gel column chromatography (ethyl acetate/petroleum ether $=1 / 7$ ) to give 3 (2.40 g, 76\%). White solid; mp 256.1-257.8 ${ }^{\circ} \mathrm{C} ;{ }^{1} \mathrm{H}$ NMR $\left(600 \mathrm{MHz}, \mathrm{CDCl}_{3}\right) \delta 4.68(\mathrm{~d}, 1 \mathrm{H}, J 1.8 \mathrm{~Hz},-\mathrm{C}=\mathrm{CH}), 4.58$ (s, $1 \mathrm{H},-\mathrm{C}=\mathrm{CH}), 4.47(\mathrm{dd}, 1 \mathrm{H}, J 11.0,5.4 \mathrm{~Hz}, \mathrm{AcO}-\mathrm{CH})$, 3.85-3.74 (m, $\left.1 \mathrm{H}, \mathrm{CH}_{2}-\mathrm{O}\right), 3.33$ (d, $1 \mathrm{H}, J 10.8 \mathrm{~Hz}, \mathrm{CH}_{2}-\mathrm{O}$ ), 2.38 (td, 1H, J 11.0, $5.8 \mathrm{~Hz}), 2.04$ (s, 3H, $\left.\mathrm{CH}_{3}-\mathrm{COO}\right), 1.69$ (s, 3H, $\left.\mathrm{CH}_{3}-\mathrm{C}=\mathrm{C}\right), 1.02\left(\mathrm{~s}, 3 \mathrm{H},-\mathrm{CH}_{3}\right), 0.97\left(\mathrm{~s}, 3 \mathrm{H},-\mathrm{CH}_{3}\right.$ ), 0.88-0.81 (m, 9H, $\left.-\mathrm{CH}_{3} \times 3\right) ;{ }^{13} \mathrm{C}$ NMR $\left(150 \mathrm{MHz}, \mathrm{CDCl}_{3}\right)$ $\delta$ 171.0, 150.5, 109.7, 80.9, 60.6, 55.4, 50.3, 48.7, 47.8, 47.8, 42.7, 40.9, 38.4, 37.8, 37.3, 37.1, 34.2, 34.0, 29.7, 29.2, 27.9, 27.0, 25.2, 23.7, 21.3, 20.8, 19.1, 18.2, 16.5, 16.2, 16.0, 14.7; MS (ESI) $m / z,[\mathbf{M}+\mathrm{H}]^{+}: 485.4$.

\section{3-O-Acetyl-betulinicaldehyde (4)}

To a solution of 3-O-acetyl-betulin $(3,300 \mathrm{mg}$, $0.6 \mathrm{mmol})$ in $\mathrm{CH}_{2} \mathrm{Cl}_{2}(20 \mathrm{~mL})$, it was added pyridinium chlorochromate (PCC, $400 \mathrm{mg}, 1.8 \mathrm{mmol})$. The reaction mixture was stirred at $35^{\circ} \mathrm{C}$ for $1 \mathrm{~h}$. Then silica gel $(1.50 \mathrm{~g})$ was added into mixture and concentrated to a dry powder. The crude product was purified by silica gel column chromatography to give 4 (240 mg, 80\%). White solid; mp 270.2-271.8 ${ }^{\circ} \mathrm{C} ;{ }^{1} \mathrm{H}$ NMR $\left(600 \mathrm{MHz}, \mathrm{CDCl}_{3}\right) \delta 9.67(\mathrm{~d}$, $1 \mathrm{H}, J 1.1 \mathrm{~Hz},-\mathrm{CHO}), 4.76$ (d, 1H, J 0.9 Hz, C=C-H), 4.63 (s, 1H, C=C-H), 4.47 (dd, 1H, J 10.9, $5.5 \mathrm{~Hz}, \mathrm{AcO}-\mathrm{CH}$ ), 
$2.86(\mathrm{td}, 1 \mathrm{H}, J 11.2,5.9 \mathrm{~Hz}), 2.04$ (s, 3H, $\left.\mathrm{CH}_{3}-\mathrm{COO}\right), 1.70$ $\left(\mathrm{s}, 3 \mathrm{H},-\mathrm{CH}_{3}\right), 0.97\left(\mathrm{~s}, 3 \mathrm{H},-\mathrm{CH}_{3}\right), 0.92\left(\mathrm{~s}, 3 \mathrm{H},-\mathrm{CH}_{3}\right), 0.84$ $\left(\mathrm{d}, 9 \mathrm{H}, J 8.5 \mathrm{~Hz},-\mathrm{CH}_{3} \times 3\right) ;{ }^{13} \mathrm{C} \mathrm{NMR}\left(150 \mathrm{MHz}, \mathrm{CDCl}_{3}\right)$ $\delta$ 206.7, 171.0, 149.7, 110.2, 80.9, 59.3, 55.4, 50.4, 48.1, 47.6, 42.6, 40.8, 38.7, 38.4, 37.8, 37.1, 34.3, 33.2, 29.8, $29.2,28.8,27.9,25.5,23.7,21.3,20.7,19.0,18.2,16.5$, $16.2,15.9,14.2$; MS (ESI) $m / z,[\mathrm{M}+\mathrm{H}]^{+}: 483.4$.

\section{Betulinicaldehyde (5)}

The solution of 3-O-acetyl-betulinicaldehyde (4, $200 \mathrm{mg}, 0.4 \mathrm{mmol})$ in $2 \% \mathrm{NaOH}-\mathrm{MeOH}(10 \mathrm{~mL})$ was stirred for $2 \mathrm{~h}$ at $80{ }^{\circ} \mathrm{C}$. The solution was evaporated and then redissolved with $\mathrm{CH}_{2} \mathrm{Cl}_{2}(100 \mathrm{~mL})$, washed with brine twice and dried over anhydrous $\mathrm{Na}_{2} \mathrm{SO}_{4}$. The solvent was evaporated and purified by silica gel column chromatography (ethyl acetate/petroleum ether $=1 / 10$ ) to

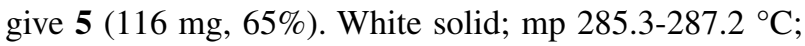
${ }^{1} \mathrm{H}$ NMR $\left(600 \mathrm{MHz}, \mathrm{CDCl}_{3}\right) \delta 9.68(\mathrm{~d}, 1 \mathrm{H}, J 1.3 \mathrm{~Hz}$, -CHO), 4.76 (s, 1H, C=C-H), $4.63(\mathrm{~s}, 1 \mathrm{H}, \mathrm{C}=\mathrm{C}-\mathrm{H}), 3.18$ (dd, 1H, J 11.5, 4.7 Hz, O-C-H), 2.86 (td, 1H, J 11.2, $5.9 \mathrm{~Hz}, \mathrm{C}=\mathrm{C}-\mathrm{CH}-), 1.70\left(\mathrm{~s}, 3 \mathrm{H}, \mathrm{CH}_{3}-\mathrm{C}=\mathrm{C}\right), 0.97(\mathrm{~s}$, $\left.3 \mathrm{H},-\mathrm{CH}_{3}\right), 0.95\left(\mathrm{~s}, 3 \mathrm{H},-\mathrm{CH}_{3}\right), 0.92\left(\mathrm{~s}, 3 \mathrm{H},-\mathrm{CH}_{3}\right), 0.82$ $\left(\mathrm{s}, 3 \mathrm{H},-\mathrm{CH}_{3}\right), 0.75\left(\mathrm{~s}, 3 \mathrm{H},-\mathrm{CH}_{3}\right) ;{ }^{13} \mathrm{C} \mathrm{NMR}(150 \mathrm{MHz}$, $\left.\mathrm{CDCl}_{3}\right) \delta 206.7,149.7,110.2$, 79.0, 59.3, 55.3, 50.5, 48.1, $47.5,42.6,40.8,38.8,38.7,38.7,37.2,34.3,33.2,29.9$, $29.3,28.8,28.0,27.4,25.5,20.8,19.0,18.3,16.1,15.9$, 15.4, 14.3; MS (ESI) $m / z,[\mathrm{M}+\mathrm{H}]^{+}: 441.4$.

\section{8-Hydrazonomethyl-betulin (6)}

To a solution of betulinicaldehyde $(\mathbf{5}, 1.55 \mathrm{~g}, 3.5 \mathrm{mmol})$ in ethanol $(80 \mathrm{~mL})$, it was added $85 \%$ hydrazine hydrate $(2 \mathrm{~mL})$. The reaction mixture was stirred at $40{ }^{\circ} \mathrm{C}$ for $5 \mathrm{~h}$. The solvent was evaporated and purified by silica gel column chromatography (ethyl acetate/petroleum ether $=1 / 1)$ to give $6(1.25 \mathrm{~g}, 70 \%)$. White solid; $\mathrm{mp}$ 243.5-245.0 ${ }^{\circ} \mathrm{C} ;{ }^{1} \mathrm{H} \mathrm{NMR}\left(600 \mathrm{MHz}, \mathrm{CDCl}_{3}\right) \delta 7.25(\mathrm{~d}, 2 \mathrm{H}$, $J 22.3 \mathrm{~Hz}, \mathrm{NH}_{2}$ ), 5.14 (s, 1H, N=CH), 4.71 (s, 1H, C=C-H), 4.59 (s, 1H, C=C-H), 3.18 (dd, 1H, J 11.2, $4.2 \mathrm{~Hz}, \mathrm{OH})$, 1.69 (s, 3H, $\left.\mathrm{CH}_{3}\right), 0.98$ (t, 9H, J 9.4 Hz, $\left.\mathrm{CH}_{3} \times 3\right), 0.93-$ $0.88(\mathrm{~m}, 1 \mathrm{H}), 0.82\left(\mathrm{~s}, 1 \mathrm{H}, \mathrm{CH}_{3}\right), 0.76\left(\mathrm{~s}, 3 \mathrm{H}, \mathrm{CH}_{3}\right), 0.68$ $(\mathrm{d}, 1 \mathrm{H}, J 9.3 \mathrm{~Hz}) ;{ }^{13} \mathrm{C} \mathrm{NMR}\left(150 \mathrm{MHz}, \mathrm{CDCl}_{3}\right) \delta 150.3$, 150.1, 109.8, 79.0, 55.3, 50.4, 50.2, 49.3, 48.0, 42.8, 40.9, $38.9,38.7,38.4,37.3,37.2,34.3,32.7,30.0,28.0,27.9$, $27.4,25.3,20.9,19.2,18.3,16.1,16.1,15.4,14.7$; MS (ESI) $\mathrm{m} / \mathrm{z},[\mathrm{M}+\mathrm{H}]^{+}: 445.4$.

\section{General procedure for synthesis of compounds 7a-7o}

To a solution of 28-hydrazonomethyl-betulin (6, $1 \mathrm{mmol})$ in ethanol $(20 \mathrm{~mL})$, it was added aldehyde substituent $(2 \mathrm{mmol})$ and five drops of acetic acid. The reaction mixture was stirred at $30{ }^{\circ} \mathrm{C}$ for $5-10 \mathrm{~h}$ till no material. The solvent was evaporated and purified by silica gel column chromatography (dichloromethane/methanol) to get pure target compounds 7a-7o.

\section{Betulin-28-(benzylidene)hydrazone (7a)}

White solid; 73\%; ${ }^{1} \mathrm{H}$ NMR (600 MHz, $\left.\mathrm{CDCl}_{3}\right) \delta 8.50$ $(\mathrm{s}, 1 \mathrm{H}), 8.12(\mathrm{~s}, 1 \mathrm{H}), 7.82(\mathrm{~m}, 2 \mathrm{H}), 7.45(\mathrm{~m}, 2 \mathrm{H}), 4.74(\mathrm{~s}$, $1 \mathrm{H}), 4.62(\mathrm{~s}, 1 \mathrm{H}), 3.18(\mathrm{dd}, 1 \mathrm{H}, J 11.5,4.6 \mathrm{~Hz}, \mathrm{OH}), 2.66$ (m, 1H, H3), 2.22-2.13 (m, 1H), 2.02 (s, 1H), 1.94 (m, $1 \mathrm{H}), 1.87(\mathrm{~m}, 1 \mathrm{H}), 1.73\left(\mathrm{~s}, 3 \mathrm{H}, \mathrm{CH}_{3}\right), 1.69-1.10(\mathrm{~m}, 18 \mathrm{H})$, 1.00 (s, 3H, $\left.\mathrm{CH}_{3}\right), 0.97$ (m, 6H, $\left.\mathrm{CH}_{3}\right), 0.87$ (m, 2H), 0.81 (s, 3H, $\left.\mathrm{CH}_{3}\right), 0.75$ (s, 3H, $\left.\mathrm{CH}_{3}\right), 0.68(\mathrm{~d}, 1 \mathrm{H}, J 11.2 \mathrm{~Hz})$; ${ }^{13} \mathrm{C}$ NMR $\left(150 \mathrm{MHz}, \mathrm{CDCl}_{3}\right) \delta 169.8$ (C-28), 160.5 $(\mathrm{C}=\mathrm{N}), 150.0$ (C-20), 134.1 (C-Ar), 131.0 (C-Ar), 128.8 (C-Ar), 128.7 (C-Ar), 128.6 (C-Ar), 128.4 (C-Ar), 109.9 (C-29), 79.0 (C-3), 55.3 (C-5), 50.4 (C-9), 49.5 (C-19), 47.9 (C-17), 46.8 (C-18), 42.9 (C-14), 40.9 (C-8), 38.8 (C-4), 38.7 (C-1), 37.3 (C-13), 37.2 (C-10), 34.8 (C-7), 34.3 (C-22), 32.2 (C-21), 29.9 (C-16), 28.1 (C-23), 27.5 (C-2), 27.2 (C-15), 25.3 (C-12), 20.8 (C-11), 19.2 (C-30), 18.3 (C-6), 16.1 (C-25), 16.0 (C-26), 15.4 (C-24), 14.7 (C-27); HRMS (ESI) $m / z$, calcd. for $\mathrm{C}_{37} \mathrm{H}_{54} \mathrm{~N}_{2} \mathrm{O}[\mathrm{M}+\mathrm{H}]^{+}$: 543.4314, found: 543.4312 .

\section{Betulin-28-(4-fluoro-benzylidene)hydrazone (7b)}

White solid; 77\%; ${ }^{1} \mathrm{H}$ NMR (600 MHz, $\left.\mathrm{CDCl}_{3}\right) \delta 8.48$ $(\mathrm{s}, 1 \mathrm{H}), 8.12(\mathrm{~s}, 1 \mathrm{H}), 7.80(\mathrm{dd}, 2 \mathrm{H}, J 8.7,5.5 \mathrm{~Hz}), 7.12(\mathrm{t}$, $2 \mathrm{H}, J 8.6 \mathrm{~Hz}), 4.74(\mathrm{~s}, 1 \mathrm{H}), 4.62(\mathrm{~s}, 1 \mathrm{H}), 3.19$ (dd, 1H, $J$ 11.5, $4.7 \mathrm{~Hz}, \mathrm{OH}), 2.66$ (m, 1H, H3), 2.16 (m, 1H), 2.00 $(\mathrm{m}, 1 \mathrm{H}), 1.94(\mathrm{~m}, 1 \mathrm{H}), 1.86(\mathrm{~m}, 1 \mathrm{H}), 1.75(\mathrm{~s}, 1 \mathrm{H}), 1.73$ (s, 3H, $\left.\mathrm{CH}_{3}\right), 1.68-1.10(\mathrm{~m}, 18 \mathrm{H}), 1.00(\mathrm{~d}, 3 \mathrm{H}, J 7.7 \mathrm{~Hz}$, $\left.\mathrm{CH}_{3}\right), 0.97\left(\mathrm{~s}, \mathrm{CH}_{3}\right), 0.91(\mathrm{~m}, 1 \mathrm{H}), 0.81\left(\mathrm{~s}, 3 \mathrm{H}, \mathrm{CH}_{3}\right), 0.76$ (s, 3H, $\left.\mathrm{CH}_{3}\right), 0.68(\mathrm{~d}, 1 \mathrm{H}, J 11.2 \mathrm{~Hz}) ;{ }^{13} \mathrm{C} \mathrm{NMR}(150 \mathrm{MHz}$, $\left.\mathrm{CDCl}_{3}\right) \delta 170.1(\mathrm{C}-28), 159.3(\mathrm{C}=\mathrm{N}), 150.0(\mathrm{C}-20), 145.0$ (C-Ar), 130.4 (C-Ar), 130.3 (C-Ar), 116.0 (C-Ar), 115.8 (C-Ar), 110.0 (C-29), 78.9 (C-3), 55.3 (C-5), 50.4 (C-9), 49.5 (C-19), 47.9 (C-17), 42.9 (C-14), 40.9 (C-8), 38.8 (C-4), 38.7 (C-1), 37.3 (C-13), 37.2 (C-10), 34.8 (C-7), 34.3 (C-22), 32.1 (C-21), 29.7 (C-16), 28.1 (C-23), 27.4 (C-2), 27.2 (C-15), 25.3 (C-12), 20.8 (C-11), 19.1 (C-30), 18.3 (C-6), 16.1 (C-25), 16.0 (C-26), 15.4 (C-24), 14.7 (C-27); HRMS (ESI) $m / z$, calcd. for $\mathrm{C}_{37} \mathrm{H}_{53} \mathrm{FN}_{2} \mathrm{O}[\mathrm{M}+\mathrm{H}]^{+}$: 561.4220, found: 561.4217 .

\section{Betulin-28-(4-chloro-benzylidene)hydrazone (7c)}

Pale yellow solid; 75\%; ${ }^{1} \mathrm{H}$ NMR $\left(600 \mathrm{MHz}, \mathrm{CDCl}_{3}\right)$ $\delta 8.76(\mathrm{~s}, 1 \mathrm{H}), 8.11(\mathrm{~s}, 1 \mathrm{H}), 8.05(\mathrm{~m}, 1 \mathrm{H}), 7.44(\mathrm{~m}, 1 \mathrm{H})$, 7.25-7.18 (m, 1H), 7.12 (dd, J 20.6, $10.4 \mathrm{~Hz}, 1 \mathrm{H}), 4.74$ (s, 1H), 4.62 (s, 1H), $3.19(\mathrm{dd}, 1 \mathrm{H}, J 11.5,4.7 \mathrm{~Hz}), 2.65$ (m, 1H), 2.24-2.14 (m, 1H), 2.09-2.00 (m, 1H), 1.99-1.91 
(m, 2H), 1.89-1.85 (m, 1H), $1.75(\mathrm{~m}, 1 \mathrm{H}), 1.73(\mathrm{~d}, 3 \mathrm{H}$, $\left.J 7.6 \mathrm{~Hz}, \mathrm{CH}_{3}\right), 1.70-1.07(\mathrm{~m}, 17 \mathrm{H}), 1.01(\mathrm{~d}, 3 \mathrm{H}, J 8.3 \mathrm{~Hz}$, $\left.\mathrm{CH}_{3}\right), 0.99-0.95\left(\mathrm{~s}, 6 \mathrm{H}, \mathrm{CH}_{3}\right), 0.94-0.87(\mathrm{~m}, 1 \mathrm{H}), 0.81$ (s, $\left.3 \mathrm{H}, \mathrm{CH}_{3}\right), 0.76\left(\mathrm{~s}, 3 \mathrm{H}, \mathrm{CH}_{3}\right), 0.71-0.65(\mathrm{~m}, 1 \mathrm{H}) ;{ }^{13} \mathrm{C} \mathrm{NMR}$ $\left(150 \mathrm{MHz}, \mathrm{CDCl}_{3}\right) \delta 170.2$ (C-28), 153.7 (C-20), 145.0 (C-Ar), 132.6 (C-Ar), 127.6 (C-Ar), 124.4 (C-Ar), 116.0 (C-Ar), 110.0 (C-29), 78.9 (C-3), 55.3 (C-5), 50.4 (C-9), 49.5 (C-19), 47.9 (C-17), 42.8 (C-14), 41.0 (C-8), 38.8 (C-4), 38.7 (C-1), 37.3 (C-13), 37.2 (C-10), 34.8 (C-7), 34.3 (C-22), 32.1 (C-21), 29.9 (C-16), 28.1 (C-23), 27.4 (C-15), 27.2 (C-2), 25.3 (C-12), 20.8 (C-11), 20.7 (C-30), 19.2 (C-30), 18.3 (C-6), 16.1 (C-25), 15.9 (C-26), 15.4 (C-24), 14.7 (C-27); HRMS (ESI) $\mathrm{m} / z$, calcd. for $\mathrm{C}_{37} \mathrm{H}_{53} \mathrm{ClN}_{2} \mathrm{O}$ $[\mathrm{M}+\mathrm{H}]^{+}: 577.3925$, found: 577.3921 .

\section{Betulin-28-(4-bromo-benzylidene)hydrazone (7d)}

Pale yellow solid; $72 \%$; ${ }^{1} \mathrm{H}$ NMR $\left(600 \mathrm{MHz}, \mathrm{CDCl}_{3}\right)$ $\delta 8.44(\mathrm{~s}, 1 \mathrm{H}), 8.11(\mathrm{~s}, 1 \mathrm{H}), 7.69(\mathrm{~m}, 2 \mathrm{H}), 7.58(\mathrm{dd}, 2 \mathrm{H}$, $J$ 14.5, $8.4 \mathrm{~Hz}), 4.74(\mathrm{~s}, 1 \mathrm{H}), 4.62(\mathrm{~s}, 1 \mathrm{H}), 3.20(\mathrm{~m}, 1 \mathrm{H})$, 2.70-2.61 (m, 1H), $2.20(\mathrm{~m}, 1 \mathrm{H}), 2.02(\mathrm{~m}, 1 \mathrm{H}), 1.94(\mathrm{~m}$, $1 \mathrm{H}), 1.85(\mathrm{~m}, 1 \mathrm{H}), 1.73\left(\mathrm{~s}, 3 \mathrm{H}, \mathrm{CH}_{3}\right), 1.67-1.10(\mathrm{~m}, 18 \mathrm{H})$, $1.00\left(\mathrm{~s}, 3 \mathrm{H}, \mathrm{CH}_{3}\right), 0.97\left(\mathrm{~s}, 6 \mathrm{H}, \mathrm{CH}_{3}\right), 0.89(\mathrm{~m}, 2 \mathrm{H}), 0.81$ (s, $\left.3 \mathrm{H}, \mathrm{CH}_{3}\right), 0.76$ (s, 3H, $\left.\mathrm{CH}_{3}\right), 0.71-0.67(\mathrm{~m}, 1 \mathrm{H}) ;{ }^{13} \mathrm{C} \mathrm{NMR}$ $\left(150 \mathrm{MHz}, \mathrm{CDCl}_{3}\right) \delta 170.4(\mathrm{C}-28), 159.3(\mathrm{C}=\mathrm{N}), 149.9$ (C-20), 133.0 (C-Ar), 132.1 (C-Ar), 132.0 (C-Ar), 129.9 (C-Ar), 129.7 (C-Ar), 125.4 (C-Ar), 110.0 (C-29), 78.9 (C-3), 55.3 (C-5), 50.4 (C-9), 49.5 (C-19), 47.9 (C-17), 42.8 (C-14), 40.9 (C-8), 38.8 (C-4), 38.7 (C-1), 37.2 (C-13), 37.1 (C-10), 34.8 (C-7), 34.3 (C-22), 32.1 (C-21), 29.9 (C-16), 28.1 (C-23), 27.4 (C-2), 27.2 (C-15), 25.3 (C-12), 20.8 (C-11), 19.2 (C-30), 18.3 (C-6), 16.1 (C-25), 16.0 (C-26), 15.3 (C-24), 14.7 (C-27); HRMS (ESI) $\mathrm{m} / z$, calcd. for $\mathrm{C}_{37} \mathrm{H}_{53} \mathrm{BrN}_{2} \mathrm{O}[\mathrm{M}+\mathrm{H}]^{+}$: 623.3420, found: 623.3396.

\section{Betulin-28-(4-methyl-benzylidene)hydrazone (7e)}

White solid; 80\%; ${ }^{1} \mathrm{H}$ NMR (600 MHz, $\left.\mathrm{CDCl}_{3}\right) \delta 8.48$ $(\mathrm{s}, 1 \mathrm{H}), 8.14(\mathrm{~s}, 1 \mathrm{H}), 7.70(\mathrm{~d}, 2 \mathrm{H}, J 8.0 \mathrm{~Hz}), 7.27-7.21(\mathrm{~m}$, $2 \mathrm{H}), 4.74(\mathrm{~s}, 1 \mathrm{H}), 4.62(\mathrm{~s}, 1 \mathrm{H}), 3.23-3.15(\mathrm{~m}, 1 \mathrm{H}), 2.71-2.61$ $(\mathrm{m}, 1 \mathrm{H}), 2.40\left(\mathrm{~s}, 3 \mathrm{H}, \mathrm{Ar}-\mathrm{CH}_{3}\right), 2.16(\mathrm{~s}, 1 \mathrm{H}), 2.02(\mathrm{~s}, 1 \mathrm{H})$ 1.99-1.92 (m, 2H), $1.87(\mathrm{~m}, 1 \mathrm{H}), 1.75(\mathrm{~s}, 1 \mathrm{H}), 1.71(\mathrm{~s}, 3 \mathrm{H}$, $\left.\mathrm{CH}_{3}\right), 1.66-1.05(\mathrm{~m}, 18 \mathrm{H}), 1.00\left(\mathrm{~s}, 3 \mathrm{H}, \mathrm{CH}_{3}\right), 1.00-0.93(\mathrm{~m}$, $\left.6 \mathrm{H}, \mathrm{CH}_{3}\right), 0.91-0.83(\mathrm{~m}, 2 \mathrm{H}), 0.81\left(\mathrm{~s}, 3 \mathrm{H}, \mathrm{CH}_{3}\right), 0.75(\mathrm{~d}, 3 \mathrm{H}$, $\left.J 6.0 \mathrm{~Hz}, \mathrm{CH}_{3}\right), 0.71-0.64(\mathrm{~m}, 1 \mathrm{H}) ;{ }^{13} \mathrm{C}$ NMR $(150 \mathrm{MHz}$, $\left.\mathrm{CDCl}_{3}\right) \delta 169.7(\mathrm{C}-28), 160.7(\mathrm{C}=\mathrm{N}), 150.0(\mathrm{C}-20), 141.5$ (C-Ar), 129.6 (C-Ar), 129.5 (C-Ar), 128.6 (C-Ar), 128.5 (C-Ar), 109.9 (C-29), 79.0 (C-3), 55.3 (C-5), 50.4 (C-9), 49.5 (C-19), 47.8 (C-17), 42.8 (C-14), 40.9 (C-8), 38.8 (C-4), 38.7 (C-1), 37.2 (C-13), 37.1 (C-10), 34.8 (C-7), 34.3 (C-22), 32.1 (C-21), 29.9 (C-16), 28.0 (C-23), 27.4 (C-2), 27.2 (C-15), 25.3 (C-12), 20.8 (C-11), 19.2 (C-30), 18.2 (C-6), 16.0 (C-25), 15.9 (C-26), 15.5 (C-24), 14.7
(C-27); HRMS (ESI) $m / z$, calcd. for $\mathrm{C}_{38} \mathrm{H}_{56} \mathrm{~N}_{2} \mathrm{O}[\mathrm{M}+\mathrm{H}]^{+}$: 557.4471, found: 557.4468 .

\section{Betulin-28-(4-methoxy-benzylidene)hydrazone (7f)}

White solid; 82\%; ${ }^{1} \mathrm{H}$ NMR (600 MHz, $\left.\mathrm{CDCl}_{3}\right) \delta 8.47$ (s, 1H), $8.15(\mathrm{~s}, 1 \mathrm{H}), 7.76(\mathrm{~d}, 2 \mathrm{H}, J 8.4 \mathrm{~Hz}), 6.99-6.92(\mathrm{~m}$, $2 \mathrm{H}), 4.74(\mathrm{~s}, 1 \mathrm{H}), 4.62(\mathrm{~s}, 1 \mathrm{H}), 3.91-3.82\left(\mathrm{~m}, 3 \mathrm{H}, \mathrm{OCH}_{3}\right)$, 3.19 (dd, 1H, J 11.5, $4.7 \mathrm{~Hz}), 2.65(\mathrm{~m}, 1 \mathrm{H}), 2.20-2.13(\mathrm{~m}$, $1 \mathrm{H}), 2.01(\mathrm{~m}, 2 \mathrm{H}), 1.97-1.91(\mathrm{~m}, 2 \mathrm{H}), 1.87(\mathrm{~m}, 1 \mathrm{H}), 1.74$ (s, 3H, $\left.\mathrm{CH}_{3}\right), 1.70-1.07(\mathrm{~m}, 17 \mathrm{H}), 1.00\left(\mathrm{~s}, 3 \mathrm{H}, \mathrm{CH}_{3}\right), 0.96$ $\left(\mathrm{m}, 6 \mathrm{H}, \mathrm{CH}_{3}\right), 0.93-0.87(\mathrm{~m}, 2 \mathrm{H}), 0.81\left(\mathrm{~s}, 3 \mathrm{H}, \mathrm{CH}_{3}\right), 0.76$ $\left(\mathrm{s}, 3 \mathrm{H}, \mathrm{CH}_{3}\right), 0.68(\mathrm{~d}, 1 \mathrm{H}, J 11.1 \mathrm{~Hz}) ;{ }^{13} \mathrm{C}$ NMR $(150 \mathrm{MHz}$, $\left.\mathrm{CDCl}_{3}\right) \delta 169.8(\mathrm{C}-28), 160.3(\mathrm{C}=\mathrm{N}), 150.0(\mathrm{C}-20), 132.2$ (C-Ar), 130.2 (C-Ar), 116.0 (C-Ar), 114.8 (C-Ar), 114.3 (C-Ar), 114.2 (C-Ar), 109.9 (C-29), 79.0 (C-3), 55.5 $\left(\mathrm{OCH}_{3}\right), 55.3$ (C-5), 50.4 (C-9), 49.5 (C-19), 47.9 (C-17), 42.8 (C-14), 40.9 (C-8), 38.8 (C-4), 38.7 (C-1), 37.3 (C-13), 37.2 (C-10), 34.8 (C-7), 34.3 (C-22), 32.2 (C-21), 29.9 (C-16), 27.9 (C-23), 27.4 (C-2), 27.2 (C-15), 25.3 (C-12), 20.8 (C-11), 20.2 (C-30), 18.3 (C-6), 16.1 (C-25), 16.0 (C-26), 15.4 (C-24), 14.7 (C-27); HRMS (ESI) $\mathrm{m} / z$, calcd. for $\mathrm{C}_{38} \mathrm{H}_{56} \mathrm{~N}_{2} \mathrm{O}_{2}[\mathrm{M}+\mathrm{H}]^{+}:$573.4420, found: 573.4417.

\section{Betulin-28-(4-nitro-benzylidene)hydrazone (7g)}

Pale yellow solid; 79\%; ${ }^{1} \mathrm{H}$ NMR $\left(600 \mathrm{MHz}, \mathrm{CDCl}_{3}\right)$ $\delta 8.70(\mathrm{~s}, 1 \mathrm{H}), 8.34(\mathrm{~s}, 1 \mathrm{H}), 8.15(\mathrm{~m}, 1 \mathrm{H}), 8.10(\mathrm{~s}, 1 \mathrm{H})$, $8.08(\mathrm{~d}, 1 \mathrm{H}, J 7.7 \mathrm{~Hz}), 7.62(\mathrm{~m}, 1 \mathrm{H}), 4.76(\mathrm{~s}, 1 \mathrm{H}), 4.63$ (s, $1 \mathrm{H}), 3.19(\mathrm{dd}, 1 \mathrm{H}, J 11.5,4.6 \mathrm{~Hz}), 2.73-2.61(\mathrm{~m}, 1 \mathrm{H})$, 2.22-2.14 (m, 1H), $2.05(\mathrm{~s}, 1 \mathrm{H}), 1.97-1.91(\mathrm{~m}, 2 \mathrm{H}), 1.85$ $(\mathrm{m}, 1 \mathrm{H}), 1.76(\mathrm{~m}, 1 \mathrm{H}), 1.73\left(\mathrm{~s}, 3 \mathrm{H}, \mathrm{CH}_{3}\right), 1.70-1.06(\mathrm{~m}$, $18 \mathrm{H}), 1.02$ (s, 3H, $\left.\mathrm{CH}_{3}\right), 0.96$ (s, 6H, $\mathrm{CH}_{3}$ ), 0.93-0.87 (m, $2 \mathrm{H}), 0.81\left(\mathrm{~s}, 3 \mathrm{H}, \mathrm{CH}_{3}\right), 0.76\left(\mathrm{~s}, 3 \mathrm{H}, \mathrm{CH}_{3}\right), 0.69(\mathrm{~d}, 1 \mathrm{H}$, $J 11.2 \mathrm{~Hz}) ;{ }^{13} \mathrm{C}$ NMR $\left(150 \mathrm{MHz}, \mathrm{CDCl}_{3}\right) \delta 171.6(\mathrm{C}-28)$, $160.5(\mathrm{C}=\mathrm{N}), 149.8$ (C-20), 135.9 (C-Ar), 133.8 (C-Ar), 129.7 (C-Ar), 125.2 (C-Ar), 122.9 (C-Ar), 110.1 (C-29), 78.9 (C-3), 55.3 (C-5), 50.4 (C-9), 49.5 (C-19), 47.9 (C-17), 42.9 (C-14), 40.9 (C-8), 38.9 (C-4), 38.8 (C-1), 37.2 (C-13), 37.1 (C-10), 34.8 (C-7), 34.3 (C-22), 32.1 (C-21), 29.9 (C-16), 28.1 (C-23), 27.4 (C-2), 27.2 (C-15), 25.3 (C-12), 20.8 (C-11), 20.7 (C-30), 18.3 (C-6), 16.1 (C-25), 16.0 (C-26), 15.4 (C-24), 14.7 (C-27); HRMS (ESI) $\mathrm{m} / z$, calcd. for $\mathrm{C}_{37} \mathrm{H}_{53} \mathrm{~N}_{3} \mathrm{O}_{3}[\mathrm{M}+\mathrm{H}]^{+}$: 588.4165, found: 588.4162.

Betulin-28-(3-trifluoromethyl-benzylidene)hydrazone (7h)

Pale yellow solid; 82\%; ${ }^{1} \mathrm{H}$ NMR $\left(600 \mathrm{MHz}, \mathrm{CDCl}_{3}\right)$ $\delta 8.45(\mathrm{~s}, 1 \mathrm{H}), 8.06(\mathrm{~s}, 1 \mathrm{H}), 8.03(\mathrm{~s}, 1 \mathrm{H}), 7.87(\mathrm{~d}, 1 \mathrm{H}$, $J 7.7 \mathrm{~Hz}), 7.62(\mathrm{~d}, 1 \mathrm{H}, J 7.8 \mathrm{~Hz}), 7.49(\mathrm{t}, 1 \mathrm{H}, J 7.8 \mathrm{~Hz})$, $4.68(\mathrm{~s}, 1 \mathrm{H}), 4.56(\mathrm{~s}, 1 \mathrm{H}), 3.12(\mathrm{dd}, 1 \mathrm{H}, J 11.5,4.7 \mathrm{~Hz})$, $2.60(\mathrm{td}, 1 \mathrm{H}, J 11.1,5.2 \mathrm{~Hz}), 2.15-2.06(\mathrm{~m}, 1 \mathrm{H}), 1.98-1.92$ $(\mathrm{m}, 1 \mathrm{H}), 1.90-1.84(\mathrm{~m}, 2 \mathrm{H}), 1.79(\mathrm{~s}, 1 \mathrm{H}), 1.68(\mathrm{~m}, 1 \mathrm{H})$, 1.65 (s, 3H, $\left.\mathrm{CH}_{3}\right), 1.62-1.01(\mathrm{~m}, 17 \mathrm{H}), 0.94\left(\mathrm{~s}, 3 \mathrm{H}, \mathrm{CH}_{3}\right)$, 
$0.90\left(\mathrm{~s}, 6 \mathrm{H}, \mathrm{CH}_{3}\right), 0.83(\mathrm{~m}, 2 \mathrm{H}), 0.74\left(\mathrm{~s}, 3 \mathrm{H}, \mathrm{CH}_{3}\right), 0.68$ (s, $\left.3 \mathrm{H}, \mathrm{CH}_{3}\right), 0.62(\mathrm{~d}, 1 \mathrm{H}, J 11.2 \mathrm{~Hz}) ;{ }^{13} \mathrm{C}$ NMR $(150 \mathrm{MHz}$, $\left.\mathrm{CDCl}_{3}\right) \delta 169.9(\mathrm{C}-28), 157.7(\mathrm{C}=\mathrm{N}), 148.9(\mathrm{C}-20), 133.9$ (C-Ar), 130.6 (C-Ar), 128.2 (C-Ar), 126.3 (C-Ar), 126.2 (C-Ar), $123.8\left(\mathrm{CF}_{3}\right), 123.7$ (C-Ar), 109.0 (C-29), 77.9 (C-3), 54.3 (C-5), 50.3 (C-9), 49.4 (C-19), 48.4 (C-17), 41.8 (C-14), 39.9 (C-8), 37.8 (C-4), 37.6 (C-1), 36.2 (C-13), 36.1 (C-10), 34.8 (C-7), 33.3 (C-22), 31.1 (C-21), 29.9 (C-16), 28.9 (C-23), 27.1 (C-2), 26.9 (C-15), 24.3 (C-12), 20.8 (C-11), 19.7 (C-30), 18.2 (C-6), 17.2 (C-25), 15.1 (C-26), 15.0 (C-24), 14.3 (C-27); HRMS (ESI) $\mathrm{m} / \mathrm{z}$, calcd. for $\mathrm{C}_{38} \mathrm{H}_{53} \mathrm{~F}_{3} \mathrm{~N}_{2} \mathrm{O}[\mathrm{M}+\mathrm{H}]^{+}: 611.4188$, found: 611.4185 .

Betulin-28-(3-methoxy-4-hydroxy-benzylidene)hydrazone (7i)

Pale yellow solid; $84 \%$; ${ }^{1} \mathrm{H}$ NMR $\left(600 \mathrm{MHz}, \mathrm{CDCl}_{3}\right.$ ) $\delta 8.42(\mathrm{~s}, 1 \mathrm{H}), 8.11(\mathrm{~s}, 1 \mathrm{H}), 7.49(\mathrm{~s}, 1 \mathrm{H}), 7.17$ (dd, 1H, J 8.1, $1.7 \mathrm{~Hz}), 6.95(\mathrm{~d}, 1 \mathrm{H}, J 8.1 \mathrm{~Hz}), 6.08(\mathrm{~s}, 1 \mathrm{H}, \mathrm{Ar}-\mathrm{OH}), 4.73(\mathrm{~d}$, $1 \mathrm{H}, J 1.6 \mathrm{~Hz}), 4.62(\mathrm{~s}, 1 \mathrm{H}), 3.97\left(\mathrm{~d}, 3 \mathrm{H}, J 3.4 \mathrm{~Hz}, \mathrm{OCH}_{3}\right)$, $3.19(\mathrm{dd}, 1 \mathrm{H}, J 11.5,4.7 \mathrm{~Hz}, \mathrm{OH}), 2.66(\mathrm{~m}, 1 \mathrm{H}), 2.20-2.11$ $(\mathrm{m}, 1 \mathrm{H}), 2.01(\mathrm{~m}, 1 \mathrm{H}), 1.97-1.92(\mathrm{~m}, 2 \mathrm{H}), 1.88(\mathrm{~m}, 1 \mathrm{H})$, $1.74(\mathrm{~s}, 1 \mathrm{H}), 1.72\left(\mathrm{~s}, 3 \mathrm{H}, \mathrm{CH}_{3}\right), 1.69-1.06(\mathrm{~m}, 17 \mathrm{H}), 1.01$ (s, 3H, $\left.\mathrm{CH}_{3}\right), 0.97\left(\mathrm{~s}, 6 \mathrm{H}, \mathrm{CH}_{3}\right), 0.94-0.86(\mathrm{~m}, 2 \mathrm{H}), 0.81$ (s, $\left.3 \mathrm{H}, \mathrm{CH}_{3}\right), 0.75\left(\mathrm{~s}, 3 \mathrm{H}, \mathrm{CH}_{3}\right), 0.68(\mathrm{~d}, 1 \mathrm{H}, J 11.2 \mathrm{~Hz})$; ${ }^{13} \mathrm{C} \mathrm{NMR}\left(150 \mathrm{MHz}, \mathrm{CDCl}_{3}\right) \delta 169.0(\mathrm{C}-28), 160.5(\mathrm{C}=\mathrm{N})$, 150.1 (C-20), 148.6 (C-Ar), 146.9 (C-Ar), 124.5 (C-Ar), 114.4 (C-Ar), 109.9 (C-29), 108.5 (C-Ar), 79.0 (C-3), 56.1 $\left(\mathrm{OCH}_{3}\right), 55.3$ (C-5), 50.4 (C-9), 49.5, (C-19) 47.9 (C-17), 42.9 (C-14), 38.8 (C-8), 38.7 (C-4), 37.3 (C-1), 37.1 (C-13), 34.3 (C-10), 34.8 (C-7), 32.2 (C-22), 29.9 (C-21), 29.8 (C-16), 28.1 (C-23), 27.4 (C-2), 25.3 (C-15), 20.8 (C-12), 20.7 (C-11), 19.2 (C-30), 18.3 (C-6), 17.1 (C-25), 16.1 (C-26), 15.4 (C-24), 14.7 (C-27); HRMS (ESI) $\mathrm{m} / z$, calcd. for $\mathrm{C}_{38} \mathrm{H}_{56} \mathrm{~N}_{2} \mathrm{O}_{3}[\mathrm{M}+\mathrm{H}]^{+}:$589.4369, found: 589.4366 .

\section{Betulin-28-(2,4-dichloro-4-hydroxy-benzylidene)hydrazone} (7j)

White solid; 80\%; ${ }^{1} \mathrm{H}$ NMR (600 MHz, $\left.\mathrm{CDCl}_{3}\right) \delta 8.82$ $(\mathrm{s}, 1 \mathrm{H}), 8.09(\mathrm{~s}, 1 \mathrm{H}), 8.07(\mathrm{~s}, 1 \mathrm{H}), 7.44(\mathrm{~d}, 1 \mathrm{H}, J 2.0 \mathrm{~Hz})$, 7.30 (dd, 1H, J 8.4, $1.9 \mathrm{~Hz}), 4.74(\mathrm{~d}, 1 \mathrm{H}, J 1.3 \mathrm{~Hz}), 4.63$ (s, 1H), 3.19 (dd, $1 \mathrm{H}, J 11.5,4.6 \mathrm{~Hz}), 2.69-2.59(\mathrm{~m}, 1 \mathrm{H})$, 2.24-2.15 (m, $1 \mathrm{H}), 2.04-1.98(\mathrm{~m}, 1 \mathrm{H}), 1.96-1.89(\mathrm{~m}$, $2 \mathrm{H}), 1.89-1.82(\mathrm{~m}, 1 \mathrm{H}), 1.75(\mathrm{~m}, 1 \mathrm{H}), 1.71\left(\mathrm{~s}, 3 \mathrm{H}, \mathrm{CH}_{3}\right)$, 1.69-1.07 (m, 17H), $1.01\left(\mathrm{~s}, 3 \mathrm{H}, \mathrm{CH}_{3}\right), 0.97\left(\mathrm{~s}, 6 \mathrm{H}, \mathrm{CH}_{3}\right)$, 0.93-0.86 (m, 2H), $0.81\left(\mathrm{~s}, 3 \mathrm{H}, \mathrm{CH}_{3}\right), 0.76\left(\mathrm{~s}, 3 \mathrm{H}, \mathrm{CH}_{3}\right)$, $0.69(\mathrm{~d}, 1 \mathrm{H}, J 11.1 \mathrm{~Hz}) ;{ }^{13} \mathrm{C}$ NMR $\left(150 \mathrm{MHz}, \mathrm{CDCl}_{3}\right)$ $\delta 170.7(\mathrm{C}-28), 155.7(\mathrm{C}=\mathrm{N}), 149.9(\mathrm{C}-20), 137.2(\mathrm{C}-\mathrm{Ar})$, 136.0 (C-Ar), 130.2 (C-Ar), 129.1 (C-Ar), 128.9 (C-Ar), 127.5 (C-Ar), 110.1 (C-29), 79.0 (C-3), 55.3 (C-5), 50.4 (C-9), 49.5 (C-19), 47.9 (C-17), 42.9 (C-14), 40.9 (C-8), 38.9 (C-4), 38.8 (C-1), 37.2 (C-13), 37.1 (C-10), 34.8
(C-7), 34.3 (C-22), 32.1 (C-21), 29.8 (C-16), 28.1 (C-23), 27.4 (C-2), 25.4 (C-15), 25.3 (C-12), 20.8 (C-11), 20.6 (C-30), 18.3 (C-6), 16.1 (C-25), 16.0 (C-26), 15.4 (C-24), 14.7 (C-27); HRMS (ESI) $\mathrm{m} / \mathrm{z}$, calcd. for $\mathrm{C}_{37} \mathrm{H}_{52} \mathrm{Cl}_{2} \mathrm{~N}_{2} \mathrm{O}$ $[\mathrm{M}+\mathrm{H}]^{+}:$611.3535, found: 611.3532 .

\section{Betulin-28-(pyridin-4-ylmethylene)hydrazone (7k)}

White solid; 81\%; ${ }^{1} \mathrm{H}$ NMR (600 MHz, $\left.\mathrm{CDCl}_{3}\right) \delta 8.75$ $(\mathrm{s}, 2 \mathrm{H}), 8.43(\mathrm{~s}, 1 \mathrm{H}), 8.11(\mathrm{~s}, 1 \mathrm{H}), 7.68(\mathrm{~s}, 2 \mathrm{H}), 4.75(\mathrm{~s}, 1 \mathrm{H})$, $4.63(\mathrm{~s}, 1 \mathrm{H}), 3.19$ (dd, 1H, J 11.5, 4.6 Hz), 2.72-2.62 (m, $1 \mathrm{H}), 2.16(\mathrm{~d}, 1 \mathrm{H}, J 12.1 \mathrm{~Hz}), 2.00(\mathrm{~s}, 1 \mathrm{H}), 1.92(\mathrm{~m}, 2 \mathrm{H})$, $1.84(\mathrm{~m}, 1 \mathrm{H}), 1.76(\mathrm{~m}, 1 \mathrm{H}), 1.72\left(\mathrm{~s}, 3 \mathrm{H}, \mathrm{CH}_{3}\right), 1.69-1.09$ (m, 18H), 1.02 (s, 3H, CH $\left.\mathrm{CH}_{3}\right), 0.97$ (s, 6H, $\left.\mathrm{CH}_{3}\right), 0.90$ (m, $1 \mathrm{H}), 0.81\left(\mathrm{~s}, 3 \mathrm{H}, \mathrm{CH}_{3}\right), 0.75\left(\mathrm{~s}, 3 \mathrm{H}, \mathrm{CH}_{3}\right), 0.69(\mathrm{~d}, 1 \mathrm{H}$, $J 11.1 \mathrm{~Hz}) ;{ }^{13} \mathrm{C}$ NMR $\left(150 \mathrm{MHz}, \mathrm{CDCl}_{3}\right) \delta 171.5(\mathrm{C}-28)$, $157.8(\mathrm{C}=\mathrm{N}), 149.8$ (C-20), 149.4 (Py), 114.3 (Py), 120.4 (Py), 110.1 (C-29), 78.9 (C-3), 55.3 (C-5), 50.4 (C-9), 49.4 (C-19), 47.9 (C-17), 42.8 (C-14), 40.9 (C-8), 38.9 (C-4), 38.8 (C-1), 37.2 (C-13), 37.1 (C-10), 34.8 (C-7), 34.3 (C-22), 32.1 (C-21), 29.8 (C-16), 28.1 (C-23), 27.3 (C-2), 25.4 (C-15), 25.3 (C-12), 20.8 (C-11), 20.7 (C-30), 18.3 (C-6), 16.1 (C-25), 16.0 (C-26), 15.4 (C-24), 14.7 (C-27); HRMS (ESI) $m / z$, calcd. for $\mathrm{C}_{36} \mathrm{H}_{53} \mathrm{~N}_{3} \mathrm{O}[\mathrm{M}+\mathrm{H}]^{+}$: 544.4268, found: 544.4264 .

\section{Betulin-28-(indole-4-ylmethylene)hydrazone (7I)}

Pale yellow solid; 77\%; ${ }^{1} \mathrm{H}$ NMR $\left(600 \mathrm{MHz}, \mathrm{CDCl}_{3}\right)$ $\delta 8.84(\mathrm{~s}, 1 \mathrm{H}), 8.46(\mathrm{~s}, 1 \mathrm{H}), 8.21(\mathrm{~s}, 1 \mathrm{H}), 7.49(\mathrm{dd}, 2 \mathrm{H}$, $J$ 7.5, $4.1 \mathrm{~Hz}), 7.35(\mathrm{~s}, 1 \mathrm{H}), 7.31(\mathrm{~s}, 1 \mathrm{H}), 7.27(\mathrm{~s}, 1 \mathrm{H})$, $4.76(\mathrm{~s}, 1 \mathrm{H}), 4.63(\mathrm{~s}, 1 \mathrm{H}), 3.19(\mathrm{dd}, 1 \mathrm{H}, J 11.5,4.5 \mathrm{~Hz})$, 2.74-2.66 (m, 1H), $2.22(\mathrm{~d}, 1 \mathrm{H}, J 12.9 \mathrm{~Hz}), 2.09-2.02(\mathrm{~m}$, $1 \mathrm{H}), 2.01-1.95(\mathrm{~m}, 2 \mathrm{H}), 1.93(\mathrm{~s}, 1 \mathrm{H}), 1.76(\mathrm{~s}, 1 \mathrm{H}), 1.74(\mathrm{~s}$, $3 \mathrm{H}), \mathrm{CH}_{3}, 1.70-1.08(\mathrm{~m}, 18 \mathrm{H}), 1.02\left(\mathrm{~s}, 3 \mathrm{H}, \mathrm{CH}_{3}\right), 0.97(\mathrm{~s}$, $\left.6 \mathrm{H}, \mathrm{CH}_{3}\right), 0.93-0.84(\mathrm{~m}, 2 \mathrm{H}), 0.80\left(\mathrm{~s}, 3 \mathrm{H}, \mathrm{CH}_{3}\right), 0.75$ (s, $\left.3 \mathrm{H}, \mathrm{CH}_{3}\right), 0.69(\mathrm{~d}, 1 \mathrm{H}, J 11.2 \mathrm{~Hz}) ;{ }^{13} \mathrm{C}$ NMR $(150 \mathrm{MHz}$, $\left.\mathrm{CDCl}_{3}\right) \delta$ 169.2 (C-28), $161.1(\mathrm{C}=\mathrm{N}), 150.1(\mathrm{C}-20), 136.3$ (C-Ar), 126.0 (C-Ar), 125.8 (C-Ar), 125.6 (C-Ar), 123.1 (C-Ar), 121.7 (C-Ar), 113.9 (C-Ar), 109.9 (C-29), 103.4 (C-Ar), 79.0 (C-3), 55.3 (C-5), 50.4 (C-9), 49.5 (C-19), 47.9 (C-17), 42.8 (C-14), 40.9 (C-8), 38.8 (C-4), 38.7 (C-1), 37.4 (C-13), 37.1 (C-10), 34.8 (C-7), 34.3 (C-22), 32.2 (C-21), 29.8 (C-16), 28.2 (C-23), 27.4 (C-2), 25.4 (C-15), 25.3 (C-12), 20.8 (C-11), 20.7 (C-30), 18.3 (C-6), 16.1 (C-25), 16.0 (C-26), 15.3 (C-24), 14.7 (C-27); HRMS (ESI) $\mathrm{m} / z$, calcd. for $\mathrm{C}_{39} \mathrm{H}_{55} \mathrm{~N}_{3} \mathrm{O}[\mathrm{M}+\mathrm{H}]^{+}: 582.4421$, found: 582.4420 .

\section{Betulin-28-(quinolin-4-ylmethylene)hydrazone (7m)}

Pale yellow solid; $78 \%$; ${ }^{1} \mathrm{H}$ NMR $\left(600 \mathrm{MHz}, \mathrm{CDCl}_{3}\right)$ $\delta 9.14(\mathrm{~s}, 1 \mathrm{H}), 9.02(\mathrm{~d}, 1 \mathrm{H}, J 4.5 \mathrm{~Hz}), 8.66(\mathrm{~d}, 1 \mathrm{H}, J 8.4 \mathrm{~Hz})$, $8.22(\mathrm{~d}, 2 \mathrm{H}, J 6.2 \mathrm{~Hz}), 7.89$ (d, 1H, J 4.4 Hz), $7.80(\mathrm{dd}, 1 \mathrm{H}$, $J 11.2,3.9 \mathrm{~Hz}), 7.68(\mathrm{t}, 1 \mathrm{H}, J 7.2 \mathrm{~Hz}), 4.77$ (s, 1H), 4.65 (s, 
1H), $3.19(\mathrm{dd}, 1 \mathrm{H}, J 11.5,4.6 \mathrm{~Hz}), 2.71(\mathrm{~d}, 1 \mathrm{H}, J 5.0 \mathrm{~Hz})$, 2.28-2.20 (m, 1H), 2.08-2.04 (m, 2H), 1.99-1.93 (m, 2H), $1.89(\mathrm{~m}, 1 \mathrm{H}), 1.79(\mathrm{~m}, 1 \mathrm{H}), 1.74\left(\mathrm{~s}, 3 \mathrm{H}, \mathrm{CH}_{3}\right), 1.71-1.10$ $(\mathrm{m}, 18 \mathrm{H}), 1.04\left(\mathrm{~s}, 3 \mathrm{H}, \mathrm{CH}_{3}\right), 0.99$ (s, 3H, $\left.\mathrm{CH}_{3}\right), 0.97(\mathrm{~s}, 3 \mathrm{H}$, $\mathrm{CH}_{3}$ ), 0.95-0.86 (m, 2H), 0.81 (s, 3H, $\left.\mathrm{CH}_{3}\right), 0.76$ (s, 3H, $\left.\mathrm{CH}_{3}\right), 0.69(\mathrm{~d}, 1 \mathrm{H}, J 11.5 \mathrm{~Hz}) ;{ }^{13} \mathrm{C} \mathrm{NMR}\left(150 \mathrm{MHz}, \mathrm{CDCl}_{3}\right)$ $\delta 171.9(\mathrm{C}-28), 157.2(\mathrm{C}=\mathrm{N}), 149.9$ (C-20), 149.8 (C-Ar), 130.0 (C-Ar), 129.8 (C-Ar), 127.7 (C-Ar), 125.8 (C-Ar), 124.0 (C-Ar), 120.4 (C-Ar), 110.1 (C-29), 78.9 (C-3), 55.3 (C-5), 50.4 (C-9), 49.5 (C-19), 47.9 (C-17), 42.9 (C-14), 40.9 (C-8), 38.8 (C-4), 38.7 (C-1), 37.3 (C-13), 37.2 (C-10), 34.8 (C-7), 34.3 (C-22), 32.1 (C-21), 29.8 (C-16), 28.2 (C-23), 27.4 (C-2), 25.4 (C-15), 25.3 (C-12), 20.8 (C-11), 20.7 (C-30), 18.3 (C-6), 16.1 (C-25), 16.0 (C-26), 15.3 (C-24), 14.7 (C-27); HRMS (ESI) $m / z$, calcd. for $\mathrm{C}_{40} \mathrm{H}_{55} \mathrm{~N}_{3} \mathrm{O}$ $[\mathrm{M}+\mathrm{H}]^{+}:$594.4425, found: 594.4420 .

\section{Betulin-28-(thiophene-2-ylmethylene)hydrazone (7n)}

White solid; 73\%; ${ }^{1} \mathrm{H}$ NMR (600 MHz, $\left.\mathrm{CDCl}_{3}\right) \delta 8.67$ (s, 1H), $8.10(\mathrm{~s}, 1 \mathrm{H}), 7.45(\mathrm{~d}, 1 \mathrm{H}, J 5.0 \mathrm{~Hz}), 7.40(\mathrm{~d}, 1 \mathrm{H}$, $J 3.5 \mathrm{~Hz}), 7.13-7.07(\mathrm{~m}, 1 \mathrm{H}), 4.73(\mathrm{~d}, 1 \mathrm{H}, J 1.5 \mathrm{~Hz}), 4.61$ (s, 1H), 3.18 (dd, 1H, J 11.5, 4.6 Hz), 2.73-2.63 (m, 1H), $2.15(\mathrm{~m}, 1 \mathrm{H}), 2.04-1.97(\mathrm{~m}, 1 \mathrm{H}), 1.95-1.86(\mathrm{~m}, 3 \mathrm{H}), 1.74$ $(\mathrm{s}, 1 \mathrm{H}), 1.72\left(\mathrm{~s}, 3 \mathrm{H}, \mathrm{CH}_{3}\right), 1.69-1.06(\mathrm{~m}, 17 \mathrm{H}), 1.01(\mathrm{~s}$, $\left.3 \mathrm{H}, \mathrm{CH}_{3}\right), 0.96\left(\mathrm{~s}, 6 \mathrm{H}, \mathrm{CH}_{3}\right), 0.90(\mathrm{~m}, 2 \mathrm{H}), 0.80(\mathrm{~s}, 3 \mathrm{H}$, $\left.\mathrm{CH}_{3}\right), 0.74\left(\mathrm{~s}, 3 \mathrm{H}, \mathrm{CH}_{3}\right), 0.68(\mathrm{~d}, 1 \mathrm{H}, J 11.0 \mathrm{~Hz}) ;{ }^{13} \mathrm{C} \mathrm{NMR}$ $\left(150 \mathrm{MHz}, \mathrm{CDCl}_{3}\right) \delta 170.1(\mathrm{C}-28), 154.7(\mathrm{C}=\mathrm{N}), 150.0$ (C-20), 138.8 (C-Ar), 132.0 (C-Ar), 129.5 (C-Ar), 127.7 (C-Ar), 110.1 (C-Ar), 109.9 (C-29), 78.9 (C-3), 55.3 (C-5), 50.4 (C-9), 49.5 (C-19), 47.8 (C-17), 42.8 (C-14), 40.9 (C-8), 38.9 (C-4), 38.7 (C-1), 37.3 (C-13), 37.1 (C-10), 34.8 (C-7), 34.3 (C-22), 29.8 (C-16), 28.1 (C-23), 27.4 (C-2), 25.4 (C-15), 25.3 (C-12), 20.8 (C-11), 20.7 (C-30), 18.8 (C-6), 16.1 (C-25), 16.0 (C-26), 15.4 (C-24), 14.7 (C-27); HRMS (ESI) $m / z$, calcd. for $\mathrm{C}_{35} \mathrm{H}_{52} \mathrm{~N}_{2} \mathrm{OS}[\mathrm{M}+\mathrm{H}]^{+}$: 548.3878, found: 548.3875 .

\section{Betulin-28-(furan-2-ylmethylene)hydrazone (70)}

Pale yellow solid; $72 \%$; ${ }^{1} \mathrm{H}$ NMR $\left(600 \mathrm{MHz}, \mathrm{CDCl}_{3}\right)$ $\delta 8.39(\mathrm{~s}, 1 \mathrm{H}), 8.20(\mathrm{~s}, 1 \mathrm{H}), 7.58(\mathrm{~d}, 1 \mathrm{H}, J 1.3 \mathrm{~Hz}), 6.85$ (d, 1H, J 3.4 Hz), 6.53 (dd, 1H, J 3.4, $1.7 \mathrm{~Hz}), 4.72(\mathrm{~d}$, $1 \mathrm{H}, J 1.4 \mathrm{~Hz}), 4.61(\mathrm{~s}, 1 \mathrm{H}), 3.18(\mathrm{dd}, 1 \mathrm{H}, J 11.5,4.7 \mathrm{~Hz})$, 2.71-2.62 (m, $1 \mathrm{H}), 2.22-2.12(\mathrm{~m}, 1 \mathrm{H}), 2.02-1.96(\mathrm{~m}, 1 \mathrm{H})$, 1.94-1.87 (m, 2H), $1.83(\mathrm{~m}, 1 \mathrm{H}), 1.73(\mathrm{~m}, 1 \mathrm{H}), 1.70(\mathrm{~s}$, $\left.3 \mathrm{H}, \mathrm{CH}_{3}\right), 1.68-1.05(\mathrm{~m}, 18 \mathrm{H}), 1.00\left(\mathrm{~s}, 3 \mathrm{H}, \mathrm{CH}_{3}\right), 0.97$ (s, $\left.3 \mathrm{H}, \mathrm{CH}_{3}\right), 0.93$ (s, $\left.3 \mathrm{H}, \mathrm{CH}_{3}\right), 0.90(\mathrm{~m}, 2 \mathrm{H}), 0.80(\mathrm{~s}, 3 \mathrm{H}$, $\left.\mathrm{CH}_{3}\right), 0.75\left(\mathrm{~s}, 3 \mathrm{H}, \mathrm{CH}_{3}\right), 0.68(\mathrm{~d}, J 11.0 \mathrm{~Hz}, 1 \mathrm{H}) ;{ }^{13} \mathrm{C} \mathrm{NMR}$ $\left(150 \mathrm{MHz}, \mathrm{CDCl}_{3}\right) \delta 171.3(\mathrm{C}-28), 154.6(\mathrm{C}=\mathrm{N}), 149.9$ (C-20), 149.5 (C-20), 145.4 (C-Ar), 128.8 (C-Ar), 116.2 (C-Ar), 112.1 (C-Ar), 109.9 (C-29), 78.9 (C-3), 55.3 (C-5), 50.4 (C-9), 49.5 (C-19), 47.9 (C-17), 42.8 (C-14), 40.9
(C-8), 38.9 (C-4), 38.7 (C-1), 37.3 (C-13), 37.1 (C-10), 34.8 (C-7), 34.3 (C-22), 29.8 (C-16), 28.1 (C-23), 27.4 (C-2), 27.2 (C-15), 25.3 (C-12), 20.8 (C-11), 20.7 (C-30), 19.1 (C-6), 16.1 (C-25), 16.0 (C-26), 15.4 (C-24), 14.7 (C-27); HRMS (ESI) $m / z$, calcd. for $\mathrm{C}_{35} \mathrm{H}_{52} \mathrm{~N}_{2} \mathrm{O}_{2}[\mathrm{M}+\mathrm{H}]^{+}$: 533.4110, found: 533.4104 .

\section{Cells culture and MTT assays}

All cell lines were obtained from the Shanghai cell Bank of the Chinese Academy of Science. Cells were cultured in Roswell Park Memorial Institute (RPMI)-1640 medium supplemented with $10 \%$ fetal bovine serum (FBS), 100 units $\mathrm{mL}^{-1}$ of penicillin and $100 \mu \mathrm{g} \mathrm{mL} \mathrm{m}^{-1}$ streptomycin at $37^{\circ} \mathrm{C}$ in a humidified atmosphere of $5 \% \mathrm{CO}_{2}$. Cytotoxic activities of all tested compounds against four cancer cell lines were evaluated by 3-(4,5-dimethylthiazol-2yl)-2,5-diphenyltetrazolium bromide (MTT) assay. Cells were seeded into 96-well plates $\left(1 \times 10^{4}\right.$ cells per well $)$ for $24 \mathrm{~h}$. Then the cells were treated with compounds at gradient concentrations from 1 to $60 \mu \mathrm{M}$ for $48 \mathrm{~h}$ and then $10 \mu \mathrm{L}$ MTT (Sigma Chemical Co., Ltd., Milwaukee, USA) solution ( $5 \mathrm{mg} \mathrm{mL}^{-1}$ in phosphate buffered saline (PBS)) were added for $2 \mathrm{~h}$. The solution was replaced by $100 \mu \mathrm{L}$ dimethyl sulfoxide (DMSO), and the absorbance was measured at $490 \mathrm{~nm}$ on a Spectra Max 340 microplate reader. The $\mathrm{IC}_{50}$ (concentration of the tested compound that inhibits 50\% of cell growth) values were derived by SPSS $^{38}$ nonlinear regression analysis.

\section{Acridine orange (AO)/ethidium bromide (EB) staining}

The MCF-7 cells were seeded into six-well plates at a concentration of $5 \times 10^{4}$ cells per $\mathrm{mL}$. The cells were incubated overnight at $37{ }^{\circ} \mathrm{C}$ in a humidified atmosphere of $5 \% \mathrm{CO}_{2}$. Then the MCF-7 cells were treated with compound $7 \mathbf{l}(0,4,8$ and $16 \mu \mathrm{M})$ for $24 \mathrm{~h}$. The cover slip with monolayer cells was inverted on the glass slide with $20 \mu \mathrm{L}$ of AO/BE stain $\left(100 \mu \mathrm{g} \mathrm{mL}^{-1}\right)$. The fluorescence was read using an IX71SIF-3 fluorescence microscope. ${ }^{39}$

\section{Flow cytometry analysis}

The MCF-7 cells were seeded into six-well plates at a concentration of $6 \times 10^{4}$ cells per $\mathrm{mL}$. The cells were incubated overnight at $37{ }^{\circ} \mathrm{C}$ in a humidified atmosphere of $5 \% \mathrm{CO}_{2}$. Then the MCF-7 cells were treated with compound $7 \mathrm{l}(0,4,8$ and $16 \mu \mathrm{M})$ for $24 \mathrm{~h}$. The cells were collected, washed twice in PBS, and resuspended in $120 \mu \mathrm{L}$ of binding buffer. Then the cells were incubated with $5 \mu \mathrm{L}$ of annexin V-FITC and $5 \mu \mathrm{L}$ of propidium iodide (PI) staining 
solution for $15 \mathrm{~min}$ at $4{ }^{\circ} \mathrm{C}$ in the dark (annexin V-FITC/PI apoptosis detection kit, Beyotime, Shanghai, China). The cells apoptosis analysis was examined by flow cytometry and system software (BD Biosciences, San Jose, CA, USA). ${ }^{40}$

\section{Results and Discussion}

\section{Chemistry}

The general procedure for the synthesis of betulin derivatives is shown in Scheme 1. The 3-OH and 28-OH of betulin (1) were acetylated with acetic anhydride in the presence of DMAP (4-dimethylaminopyridine) in dry pyridine at room temperature to give compound $\mathbf{2}$. Compound 2 further reacted with titanium propoxide $\left(\mathrm{Ti}(i-\mathrm{PrOH})_{4}\right)$ in dry isopropyl alcohol $(i-\mathrm{PrOH})$ for selective deacetylation at C-28 to give compound $\mathbf{3}$. Then the 28-OH of betulin was oxidized to a carbonyl group in the presence of pyridinium chlorochromate (PCC) in dry dichloromethane to give compound 4. Subsequently, compound $\mathbf{4}$ was reacted with sodium hydroxide for deacetylation at C-3 to give compound $\mathbf{5}$. Then, compound $\mathbf{5}$ was reacted with hydrazine hydrate in ethanol to obtain the corresponding hydrazine 6 . At last, the resulting hydrazine $\mathbf{6}$ was reacted with different aldehyde substituents in the presence of acetic acid in ethanol to obtain target novel betulin derivatives 7a-7o.
The structures of all new compounds were characterized by HRMS, ${ }^{1} \mathrm{H}$ NMR and ${ }^{13} \mathrm{C}$ NMR spectrum methods. Taking compound $7 \mathbf{a}$ as a typical example, in the ${ }^{1} \mathrm{H}$ NMR spectrum, the chemical shifts of $8.50(\mathrm{~s}, 1 \mathrm{H}) \mathrm{ppm}$ and $8.12(\mathrm{~s}, 1 \mathrm{H}) \mathrm{ppm}$ demonstrate the formation of $-\mathrm{CH}=\mathrm{N}-\mathrm{N}=\mathrm{CH}-$ group at side chain. In addition, the chemical shifts of two $\mathrm{C}=\mathrm{N}$ bonds at 169.8 and $160.5 \mathrm{ppm}$ in the ${ }^{13} \mathrm{C}$ NMR spectrum also demonstrate the formation of $-\mathrm{CH}=\mathrm{N}-\mathrm{N}=\mathrm{CH}-$ group in compound $7 \mathbf{a}$.

\section{Evaluation of antitumor activities}

The in vitro cytotoxicities of all newly synthesized betulin derivatives 7a-7o were evaluated using MTT assays against human hepatocellular carcinoma cells (HepG2), human breast carcinoma cells (MCF-7), human colorectal cells (HCT-116) and human lung carcinoma cells (A549). Mitomycin $\mathrm{C}$ was used as the positive drug control. The cytotoxicities of all compounds were summarized as $\mathrm{IC}_{50}$ values in Table 1 . The results showed that some of the synthesized compounds displayed significant cytotoxicities toward all four tested human tumor cell lines. The results suggested the following rough structure-activity relationships considerations.

For HepG2 cell line, compounds $\mathbf{7 g}, \mathbf{7 h}, \mathbf{7 j}, \mathbf{7 k}$ and $7 \mathrm{l}$ displayed greater cytotoxic activities than betulin $\left(\mathrm{IC}_{50}=20.60 \mu \mathrm{M}\right)$. Compound 71 possessing indole

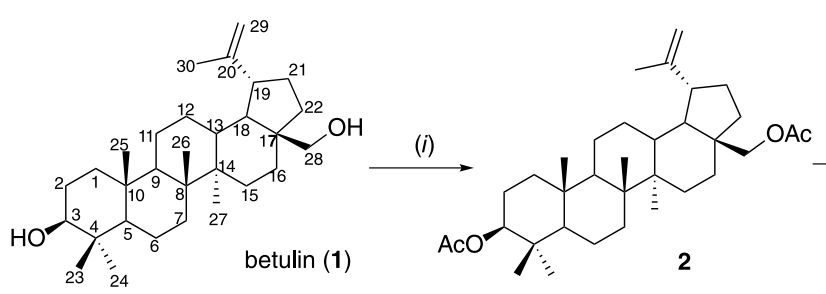

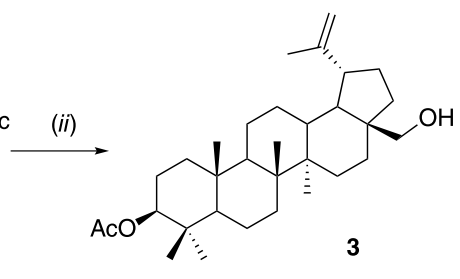<smiles>C=C(C)[C@H]1CCC2(C=O)CC[C@]34CCC5C(C)(C)C(OC(C)=O)CC[C@]5(C)C3CCC4C12</smiles>

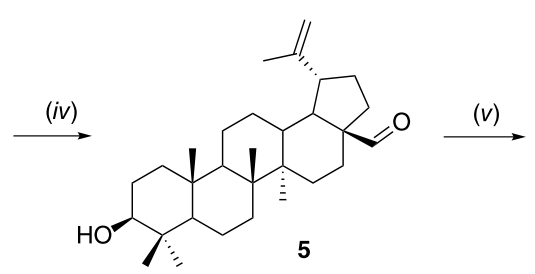

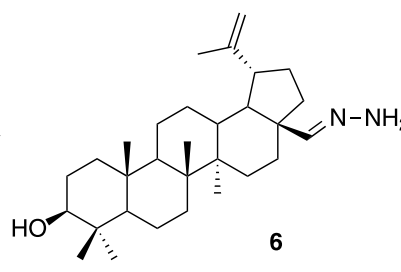

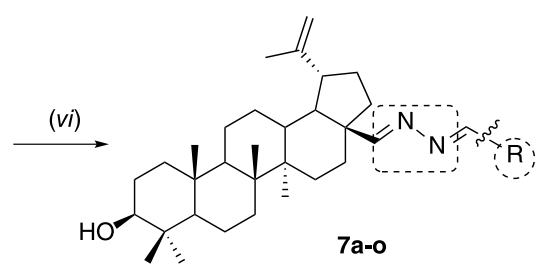<smiles>[Te][Te][Te]c1ccccc1</smiles>

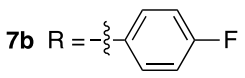<smiles>[3H]P=[As]c1ccc(Cl)cc1</smiles>

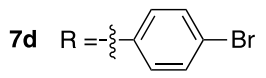<smiles></smiles><smiles>[Y][Y]=[Te][14c]1ccc(OC)cc1</smiles><smiles>O=[N+]([O-])c1ccc([Te]=[Te])cc1</smiles><smiles>FC(F)(F)c1cccc(I=P)c1</smiles>

$7 i$<smiles>[H][Y]([H])([H])c1ccc(O)c(OC)c1</smiles>

7j<smiles>[Y][Y]=[Z]([Y])c1ccncc1</smiles>

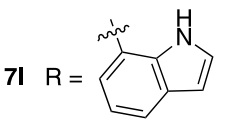<smiles>C[Te](C)([Te]=P)c1cccs1</smiles>

$70 \mathrm{R}=\sqrt[3]{3}$

Scheme 1. Synthesis of betulin derivatives 7a-7o. Reagents and conditions: $(i)$ acetic anhydride, DMAP, pyridine, r.t., 6 h, $80 \% ;(i i)$ Ti $(i-\mathrm{PrOH})_{4}, i$-PrOH, $85{ }^{\circ} \mathrm{C}, 5 \mathrm{~h}$; $76 \%$; (iii) PCC, dichloromethane, $35^{\circ} \mathrm{C}, 1 \mathrm{~h}, 80 \%$; (iv) $\mathrm{NaOH}$, methanol, $80{ }^{\circ} \mathrm{C}, 2 \mathrm{~h}, 65 \%$; (v) hydrazine hydrate, ethanol, $40{ }^{\circ} \mathrm{C}, 5 \mathrm{~h}, 70 \%$; (vi) ethanol, acetic acid, aldehyde, r.t., $2-5$ h, $72-88 \%$. 
Table 1. Cytotoxicities of compounds 7a-7o in human cancer cells

\begin{tabular}{|c|c|c|c|c|}
\hline \multirow{2}{*}{ Compound } & \multicolumn{4}{|c|}{$\mathrm{IC}_{50}{ }^{\mathrm{a}} / \mu \mathrm{M}$} \\
\hline & HepG2 & MCF-7 & HCT-116 & A549 \\
\hline $7 \mathbf{a}$ & $>60$ & $47.34 \pm 4.34$ & $>60$ & $>60$ \\
\hline $7 b$ & $27.42 \pm 0.85$ & $27.09 \pm 1.12$ & $32.14 \pm 2.13$ & $36.84 \pm 5.13$ \\
\hline $7 c$ & $21.42 \pm 2.20$ & $25.37 \pm 1.33$ & $31.15 \pm 2.65$ & $29.40 \pm 1.92$ \\
\hline $7 d$ & $25.87 \pm 1.10$ & $12.24 \pm 0.47$ & $19.53 \pm 0.64$ & $32.26 \pm 2.11$ \\
\hline $7 e$ & $34.05 \pm 2.33$ & $>60$ & $>60$ & $>60$ \\
\hline $7 f$ & $>60$ & $>60$ & $>60$ & $>60$ \\
\hline $7 g$ & $11.35 \pm 0.88$ & $10.64 \pm 0.53$ & $17.52 \pm 1.13$ & $26.77 \pm 1.40$ \\
\hline $7 \mathbf{h}$ & $14.50 \pm 1.17$ & $17.65 \pm 0.92$ & $12.55 \pm 0.87$ & $24.14 \pm 1.13$ \\
\hline $7 \mathbf{i}$ & $39.52 \pm 1.44$ & $23.80 \pm 1.30$ & $29.55 \pm 1.62$ & $40.27 \pm 1.38$ \\
\hline $7 \mathbf{j}$ & $12.93 \pm 0.67$ & $10.48 \pm 0.61$ & $16.63 \pm 0.53$ & $22.72 \pm 2.02$ \\
\hline $7 \mathbf{k}$ & $9.32 \pm 0.47$ & $8.76 \pm 0.44$ & $18.43 \pm 1.22$ & $28.55 \pm 1.33$ \\
\hline 71 & $8.60 \pm 0.84$ & $7.37 \pm 0.38$ & $14.24 \pm 1.31$ & $27.54 \pm 1.55$ \\
\hline $7 \mathrm{~m}$ & $18.27 \pm 1.23$ & $14.88 \pm 1.36$ & $28.58 \pm 0.70$ & $>60$ \\
\hline $7 n$ & $31.06 \pm 3.14$ & $28.17 \pm 1.58$ & $>60$ & $>60$ \\
\hline 70 & $34.25 \pm 1.35$ & $27.66 \pm 1.91$ & $31.54 \pm 2.46$ & $>60$ \\
\hline 1 & $20.60 \pm 1.14$ & $19.67 \pm 0.93$ & $27.46 \pm 1.33$ & $31.12 \pm 2.05$ \\
\hline Mitomycin C & $26.60 \pm 1.30$ & $13.03 \pm 1.10$ & $11.09 \pm 0.78$ & $12.36 \pm 0.99$ \\
\hline
\end{tabular}

${ }^{\mathrm{a}} \mathrm{IC}_{50}$ : concentration of the tested compound that inhibits $50 \%$ of cell growth. All data are presented as means \pm standard deviation (SD) of three independent experiments. HepG2: human hepatocellular carcinoma cells; MCF-7: human breast carcinoma cells; HCT-116: human colorectal cells; A549: human lung carcinoma cells.

group displayed significant cytotoxic activity with $\mathrm{IC}_{50}$ value of $8.60 \mu \mathrm{M}$. It is about 2.4-fold higher than betulin. Compounds $7 \mathbf{g}$ and $7 \mathbf{k}$ also displayed significant cytotoxic activities. The data showed that the incorporation of electrondonating group at the $\mathrm{C} 28$ of betulin led to significant improvement in cytotoxic activity than methyl or methoxy group. For MCF-7 cell line, compounds 7d, 7g, 7j, 7k, 7l and $7 \mathrm{~m}$ also possessed stronger cytotoxicity than that of betulin, all $\mathrm{IC}_{50}$ values lower than $15 \mu \mathrm{M}$. Among them, compound $7 \mathrm{I}$ $\left(\mathrm{IC}_{50}=7.37 \mu \mathrm{M}\right)$ was the most active, which was 2.7 -fold more potent than betulin. The results suggested that the electron-donating substitution with aromatic hydrazone side chain at the $\mathrm{C} 28$ of betulin was beneficial for compounds which displayed significant cytotoxicity against MCF-7 cells. For HCT-116 cells, only compounds $\mathbf{7 h}$ and $\mathbf{7 l}$ exhibited moderate cytotoxic activities. For A549 cells, none of the compounds showed ideal inhibitory activity.

Among the compounds under biological study, compound 71 was the most potent compound against HepG2 and MCF-7 cell lines, with $\mathrm{IC}_{50}$ values of 8.60 and $7.37 \mu \mathrm{M}$, respectively. One of the major indexes of a potent effective anti-cancer drug lies in that it can inhibit cancer cell growth, and subsequently induces apoptosis. To further investigate the cellular mechanism of this kind of new compounds, compound $\mathbf{7 l}$ was chosen for subsequent biological functions experiments in MCF-7 cells.
Preliminary investigation of the apoptosis-inducing effect of compound $7 \mathbf{I}$

Firstly, the AO/EB staining of MCF-7 cells treated with compound $7 \mathbf{l}$ was observed under a fluorescence microscope. A large number of normal cells in the control group were stained green and their nuclei were intact. As the concentration of compound 71 increased $(0,4,8$ and $16 \mu \mathrm{M}$ ), some cells showed apoptotic characteristics such as chromosome pyknosis, fragmentation and sparse cytoplasm, and the number of cells gradually increased. Furthermore, the number of early apoptotic cells and late apoptotic cells also increased, the latter was characterized by the nucleus with EB staining, orange red, concentration or bias. The necrotic cells showed uneven orange-red fluorescence and were not clearly defined and disintegrated or nearly disintegrated. The results are shown in Figure 3.

In order to confirm whether apoptosis was induced by compound 71 in tumor cells, the MCF-7 cells were doubly stained with annexin V-FITC and propidium iodide (PI). The MCF-7 cells were treated with compound $7 \mathbf{l}$ at the indicated concentrations $(0,4,8$ and $16 \mu \mathrm{M})$ for $24 \mathrm{~h}$, and the rates of apoptotic cells were detected by flow cytometry. As shown in Figure 4, after treatment with 4,8 and $16 \mu \mathrm{M}$ of $7 \mathbf{l}$ for $24 \mathrm{~h}$, the percentage of apoptosis cells was increased from 17.06 to $31.96 \%$, while the control group was only $14.90 \%$. 

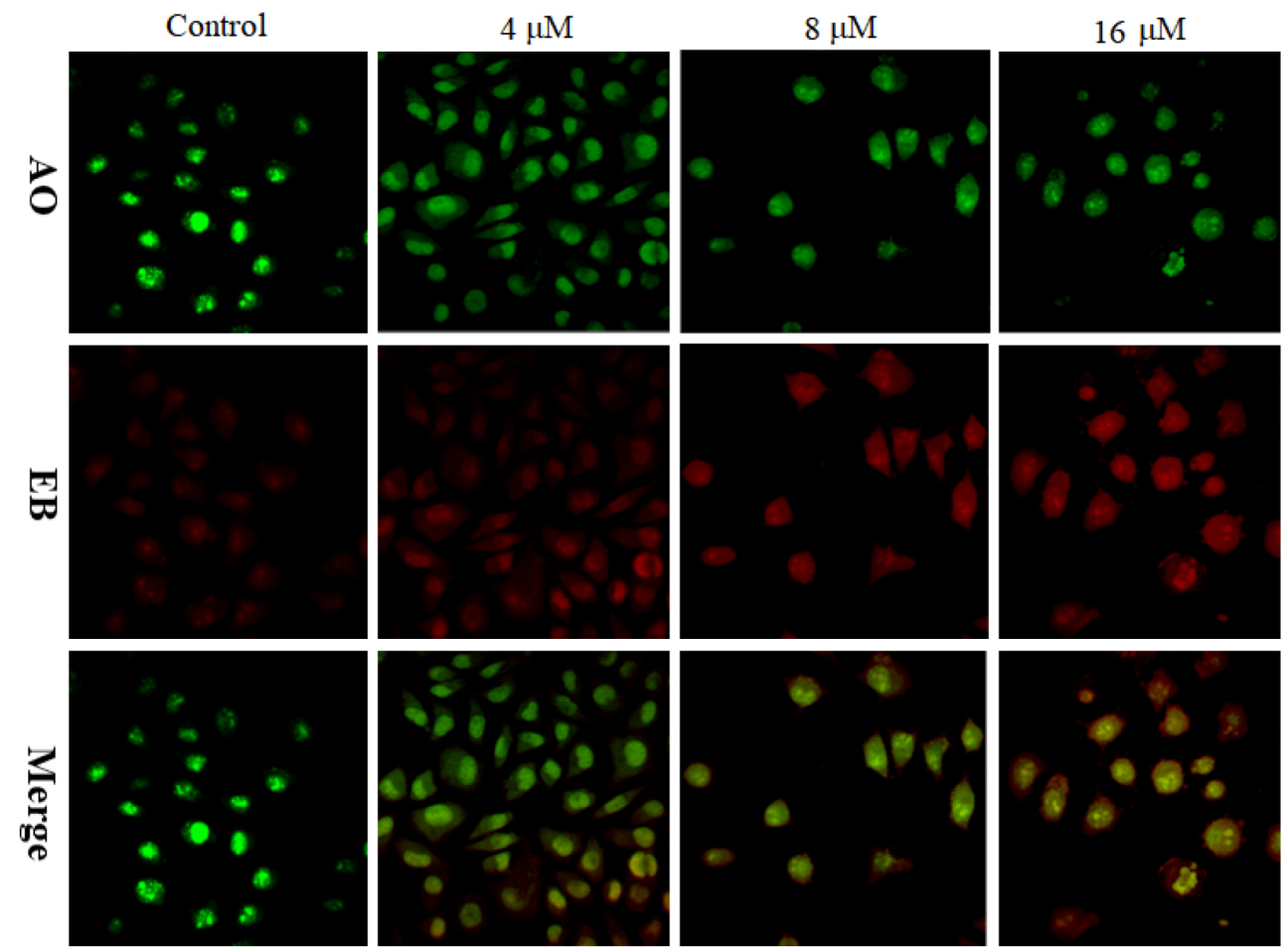

Figure 3. Compound $\mathbf{7 l}$ induced apoptosis in MCF-7 cells. MCF-7 cells were treated with compound $7 \mathbf{l}(0,4,8$ and $16 \mu \mathrm{M})$ for $24 \mathrm{~h}$ and then stained with $\mathrm{AO} / \mathrm{EB}$.
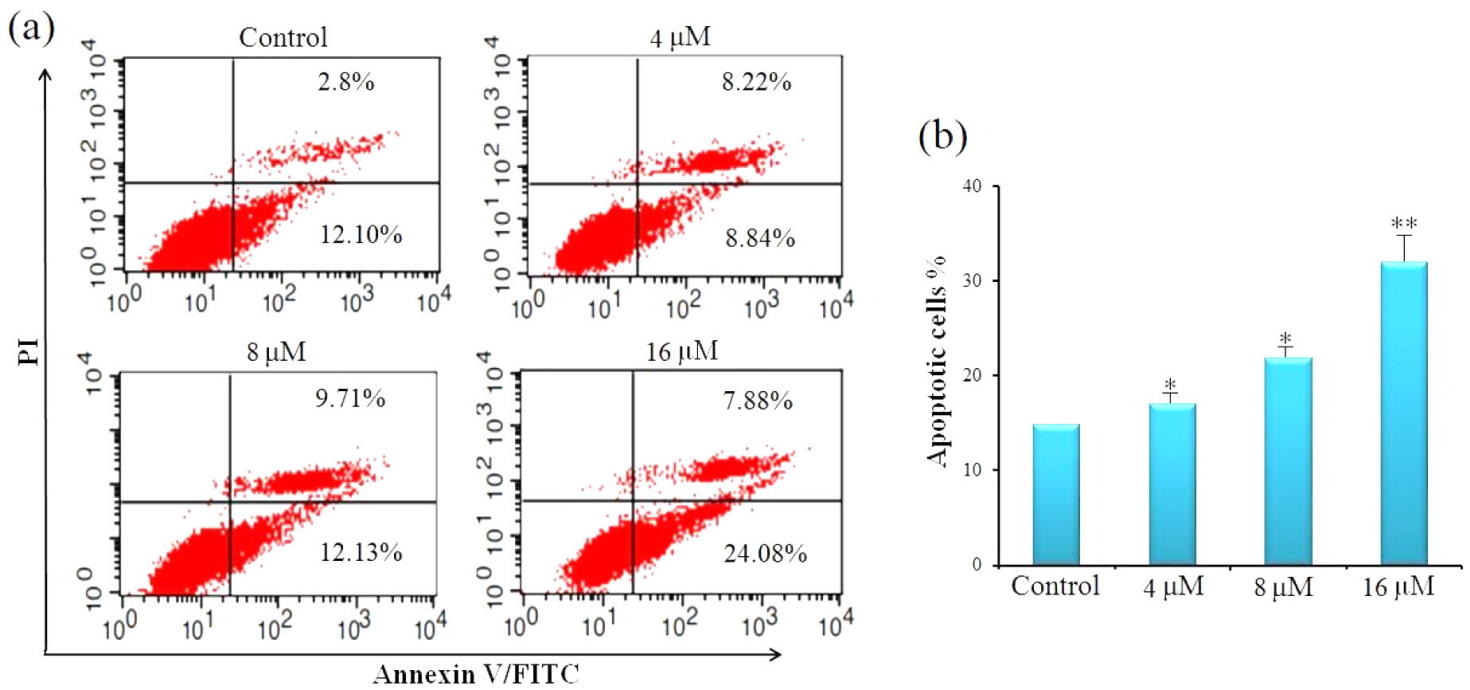

Figure 4. Compound 7l induced MCF-7 cells apoptosis. (a) MCF-7 cells were treated with compound 7l (4, 8 and $16 \mu \mathrm{M})$ for $24 \mathrm{~h}$ and then stained with annexin V-FITC/PI; (b) data were expressed as the mean \pm SEM for three independent experiments. $* P<0.05, * * P<0.01$ versus control $(0 \mu \mathrm{M})$.

Notably, the apoptosis rate of MCF-7 cells treatment with compound $\mathbf{7 1}$ increased in a dose-dependent manner. The above results suggested that compound $7 \mathbf{l}$ could induce apoptosis in MCF-7 cells significantly.

\section{Conclusions}

In summary, according to the special structural features of betulin and hydrazone group, fifteen newly betulin derivatives with aromatic hydrazone side chain on the C-28 position were designed and synthesized. All compounds were evaluated for their in vitro cytotoxicities in four human carcinoma cells (HepG2, MCF-7, HCT-116 and A549). Among them, compound 71 displayed the most potent antiproliferative with an $\mathrm{IC}_{50}$ value of $7.37 \pm 0.38 \mu \mathrm{M}$ against MCF-7 cells. Furthermore, the preliminary cellular mechanism studies indicated that compound $7 \mathbf{l}$ could induce MCF-7 cells apoptosis. The above findings indicated 
that compound $7 \mathbf{l}$ may be used as a promising skeleton for antitumor agents with improved efficacy.

\section{Supplementary Information}

Supplementary file (containing the NMR and HRMS spectra for the synthesized compounds) is available free of charge at https://jbcs.sbq.org.br as PDF file.

\section{Acknowledgments}

We gratefully acknowledge the financial support by Central Government Support Fund for the Reform and Development of Local Universities-Talent Training Support Program Project (ZYZX2019) and Qiqihar Academy of Medical Sciences Project (QY-2016B-34).

\section{Author Contributions}

M. B. was responsible for conceptualization; J. F. W., J. L. W. and J. Z. for methodology and chemistry experiments; Y. L. H., H. J. W. and Y. L. for biology experiments; J. F. W. and J. W. for writing original draft; M. B. for writing-review and editing.

\section{References}

1. Siegel, R. L.; Miller, K. D.; Jemal, A.; CA-Cancer J. Clin. 2020, 70,7 .

2. Dutta, S.; Mahalanobish, S.; Saha, S.; Ghosh, S.; Sil, P. C.; Food Chem. Toxicol. 2019, 128, 240.

3. Liu, Y.; Yang, S.; Wang, K.; Lu, J.; Bao, X.; Wang, R.; Qiu, Y.; Wang, T.; Yu, H.; Cell Proliferation 2020, 53, e12894.

4. Ahmad, R.; Khan, M. A.; Srivastava, A. N.; Gupta, A.; Srivastava, A.; Jafri, T. R.; Siddiqui, Z.; Chaubey, S.; Khan, T.; Srivastava, A. K.; Anticancer Agents Med. Chem. 2020, 20, 122.

5. Bu, M.; Li, H. L.; Wang, H. J.; Wang, J.; Lin, Y.; Ma, Y. K.; Molecules 2019, 24, 3307.

6. Ullah, A.; Baratto, L. C.; Paula, R. C.; Silva, L. H. V.; Soares, M. J.; Oliveira, B. H.; J. Braz. Chem. Soc. 2016, 27, 1245.

7. Ibrahim, H. A.; Elgindi, M. R.; Ibrahim, R. R.; El-Hosari, D. G.; Altern. Med. 2019, 19, 102.

8. Oloyede, H. O. B.; Ajiboye, H. O.; Salawu, M. O.; Ajiboye, T. O.; Microb. Pathog. 2017, 111, 338.

9. Huang, Q. X.; Chen, H. F.; Luo, X. R.; Zhang, Y. X.; Yao, X.; Zheng, X.; Curr. Med. Sci. 2018, 38, 387.

10. Xiong, J.; Kashiwada, Y.; Chen, C. H.; Qian, K.; MorrisNatschke, S. L.; Lee, K. H.; Takaishi, Y.; Bioorg. Med. Chem. 2010, 18, 6451 .

11. Wang, Q.; Li, Y.; Zheng, L.; Huang, X.; Wang, Y.; Chen, C. H.; Cheng, Y. Y.; Morris-Natschke, S. L.; Lee, K. H.; ACS Med. Chem. Lett. 2020, 11, 2290.
12. Ou, Z.; Zhao, J.; Zhu, L.; Huang, L.; Ma, Y.; Ma, C.; Luo, C.; Zhu, Z.; Yuan, Z.; Wu, J.; Li, R.; Yi, J.; Biomed. Pharmacother. 2019, 118, 109347.

13. Li, J.; Jiang, B.; Chen, C.; Fan, B.; Huang, H.; Chen, G.; Phytochemistry 2019, 166, 112076.

14. Shah, M. R.; Hizbullah, S. M. I.; Habtemariam, S.; Zarrelli, A.; Muhammad, A.; Collina, S.; Khan, I.; J. Enzyme Inhib. Med. Chem. 2016, 31, 563.

15. Wang, L.; Zhong, D.; J. Environ. Pathol., Toxicol. Oncol. 2020, $39,213$.

16. Dutta, D.; Paul, B.; Mukherjee, B.; Mondal, L.; Sen, S.; Chowdhury, C.; Debnath, M. C.; Sci. Rep. 2019, 9, 11506.

17. Zeng, A.; Hua, H.; Liu, L.; Zhao, J.; Bioorg. Med. Chem. 2019 , 27, 2546.

18. Kutkowska, J.; Strzadala, L.; Rapak, A.; Chem. Biol. Interact. 2021, 333, 109320.

19. Dubinin, M. V.; Semenova, A. A.; Ilzorkina, A. I.; Mikheeva, I. B.; Yashin, V. A.; Penkov, N. V.; Vydrina, V. A.; Ishmuratov, G. Y.; Sharapov, V. A.; Khoroshavina, E. I.; Gudkov, S. V.; Belosludtsev, K. N.; Biochim. Biophys. Acta, Biomembr. 2020, 1862, 183383.

20. Buko, V.; Kuzmitskaya, I.; Kirko, S.; Belonovskaya, E.; Naruta, E.; Lukivskaya, O.; Shlyahtun, A.; Ilyich, T.; Zakreska, A.; Zavodnik, I.; Physiol. Int. 2019, 106, 323.

21. Jiao, L.; Wang, S.; Zheng, Y.; Wang, N.; Yang, B.; Wang, D.; Yang, D.; Mei, W.; Zhao, Z.; Wang, Z.; Biochem. Pharmacol. 2019, 161, 149.

22. Härmä, V.; Haavikko, R.; Virtanen, J.; Ahonen, I.; Schukov, H. P.; Alakurtti, S.; Purev, E.; Rischer, H.; Yli-Kauhaluoma, J.; Moreira, V. M.; Nees, M.; Oksman-Caldentey, K. M.; PLoS One 2015, 10, e0126111.

23. Dehelean, C. A.; Feflea, S.; Molnár, J.; Zupko, I.; Soica, C.; Nat. Prod. Commun. 2012, 7, 981.

24. Bębenek, E.; Chrobak, E.; Marciniec, K.; Kadela-Tomanek, M.; Trynda, J.; Wietrzyk, J.; Boryczka, S.; Int. J. Mol. Sci. 2019, 20, 1372.

25. Laiolo, J.; Barbieri, C. L.; Joray, M. B.; Lanza, P. A.; Palacios, S. M.; Vera, D. M. A.; Carpinella, M. C.; Toxicology 2021, 147, 111922.

26. Boryczka, S.; Bębenek, E.; Wietrzyk, J.; Kempińska, K.; Jastrzębska, M.; Kusz, J.; Nowak, M.; Molecules 2013, 18, 4526.

27. Li, L. Y.; Peng, J. D.; Zhou, W.; Qiao, H.; Deng, X.; Li, Z. H.; Li, J. D.; Fu, Y. D.; Li, S.; Sun, K.; Liu, H. M.; Zhao, W.; Eur. J. Med. Chem. 2018, 148, 359.

28. Ma, L.W.; Wang, H. J.; Wang, J.; Liu, L.; Zhang, S.; Bu, M.; Molecules 2020, 25, 1209.

29. Han, Y. L.; Lin, Y.; Wang, Y. M.; Wang, H. J.; Li, H. L.; Wang, J.; Ma, Y. K.; Bu, M.; Heterocycles 2020, 100, 790.

30. Wang, H. J.; Bu, M.; Wang, J.; Liu, L.; Zhang, S.; Russ. J. Bioorg. Chem. 2019, 45, 585. 
31. Ibrahim, N. M.; Yosef, H. A. A.; Ewies, E. F.; Mahran, M. R. H.; Ali, M. M.; Mahmoud, A. E.; J. Braz. Chem. Soc. 2015, 26, 1086.

32. Caixeiro, J. M. R.; Gonçalves, V. T.; de Oliveira, M. C. C.; Sant'Anna, C. M. R.; Rumjanek, V. M.; da Costa, J. B. N.; J. Braz. Chem. Soc. 2012, 23, 804.

33. Su, X.; Aprahamian, I.; Chem. Soc. Rev. 2014, 43, 1963.

34. Lang, D. K.; Kaur, R.; Arora, R.; Saini, B.; Arora, S.; Anticancer Agents Med. Chem. 2020, 20, 2150.

35. Kerru, N.; Gummidi, L.; Maddila, S.; Gangu, K. K.; Jonnalagadda, S. B.; Molecules 2020, 25, 1909.

36. Desai, N.; Trivedi, A.; Pandit, U.; Dodiya, A.; Rao, V. K.; Desai, P.; Mini-Rev. Med. Chem. 2016, 16, 1500.
37. Kumar, D.; Jain, S. K.; Curr. Med. Chem. 2016, 23, 4338.

38. IBM SPSS Statistics for Windows, version 20.0; IBM Corp., Armonk, NY, 2013.

39. Yang, S. J.; Liu, M. C.; Xiang, H. M.; Zhao, Q.; Xue, W.; Yang, S.; Eur. J. Med. Chem. 2015, 102, 249.

40. Ma, L. W.; Zhang, J. L.; Wang, X. M.; Yang, J. F.; Guo, L. N.; Wang, X. L.; Song, B.; Dong, W.; Wang, W. B.; Eur. J. Med. Chem. 2021, 217, 113361.

Submitted: August 13, 2021 Published online: October 13, 2021 